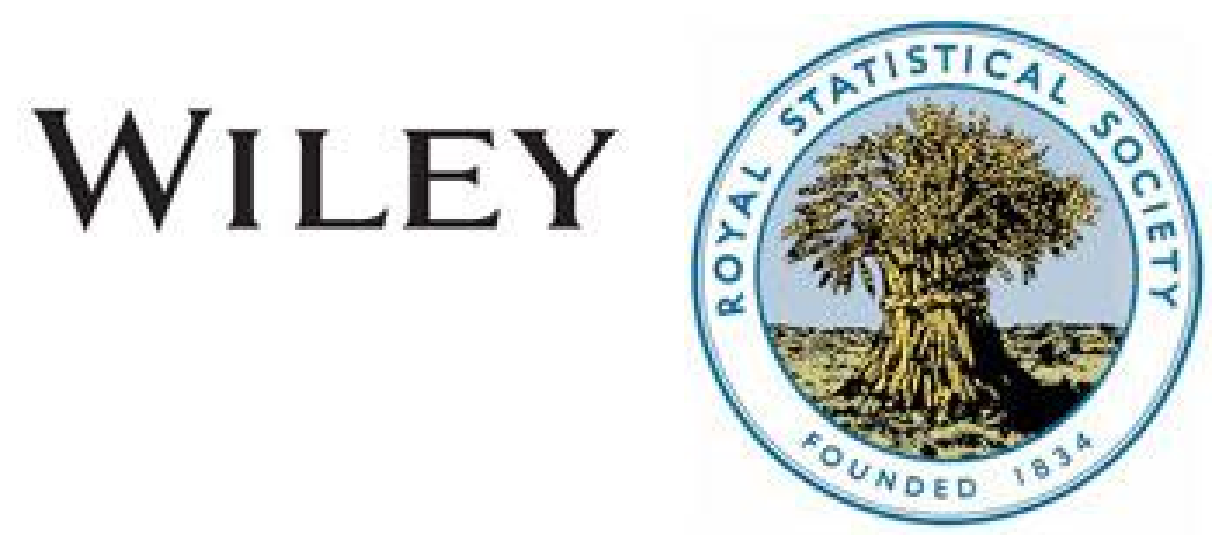

The Theory and Practice of Statistics

Author(s): Wynnard Hooper

Source: Journal of the Statistical Society of London, Vol. 46, No. 3 (Sep., 1883), pp. 461-516 Published by: Wiley for the Royal Statistical Society

Stable URL: http://www.jstor.org/stable/2979303

Accessed: 27-06-2016 09:54 UTC

Your use of the JSTOR archive indicates your acceptance of the Terms \& Conditions of Use, available at

http://about.jstor.org/terms

JSTOR is a not-for-profit service that helps scholars, researchers, and students discover, use, and build upon a wide range of content in a trusted digital archive. We use information technology and tools to increase productivity and facilitate new forms of scholarship. For more information about JSTOR, please contact support@jstor.org.

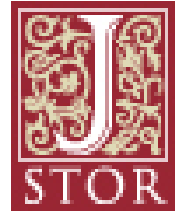

Wiley, Royal Statistical Society are collaborating with JSTOR to digitize, preserve and extend access to Journal of the Statistical Society of London 


\section{The Theory and Practice of Statistics.}

\section{(Translated and Abridged by WrNnaRd HOOPER, EsQ., from} DR. GEORGe MAYR's Work, "Die Gesetzmässigleit im Gesellschaftsleben.")

[This Paper has been a long time in type, but owing to the great press of original papers read at the Society's meetings, it has not been convenient till now to make room in the Journal for it. The thanks of the Society are due to 1)r. Mayr for his kindness in consenting to the trauslation and abridgment.EDITOR.]

TrE peculiar phenomena which are called into existence by the life of man in a state of society, differ essentially in character from the phenomena of nature. It is hardly necessary to illustrate this by a great number of examples. The causes which have produced and maintained a particular political system, can by no means be compared with those which determine the limits of the tropical or the polar regions. The increase and decrease of crime is a phenomenon, which occurs in accordance with laws which are altogether differently constituted from those relating, for instance, to variations of heat and cold, of sunshine, and of rainfall. On these grounds nothing seems more reasonable than to consider nature and society as in opposition to one another. Nevertheless, further proof is necessary to justify so marked a separation as this. First of all, it becomes evident that it is quite erroneous to place nature and humanity in absolute opposition to one another, as is often done. Man as such is attached to nature by a thousand filaments, and is himself neither the product of art, nor of spirit, but of nature. A large part of his vital activity is entirely determined by natural laws, which fulfil themselves without reference to him, and, in most cases, without the assent of any determinate volitional influence. Just as the entrance into life of the newly-born being, exhibits itself as a purely natural process, so too at his death, man pays his tribute to nature. Even the suicide does not die once for all, through his conceiving a suicidal intention, but through a natural process which be calls into activity. Hence man is justly regarded as one of the most important objects to be investigated by natural science. In this respect he is in the same category not only with animals and plants, but with the inorganic structures. Inquiries into the anatomy and physiology of man are so far from affording a contrast to the parallel investigation of other organisms, that they can only attain to decided progress by being conjoined with them in comparative inquiry.

Nevertheless, much may be observed in human affairs, and in the nlterior arrangements which remain as lasting results of human action, which cannot be treated as purely natural processes. If we 
examine more closely, we shall find that, in such cases, we have to do with peculiar forms, which owe their origin to the entry of man into a state of society. The potential development of the soul certainly lies in the purely natural product man, but the development itself is first brought about by society. In society, religious and moral feeling is awakened, in society a consciousness of right and wrong is formed. Speech itself, that conveyor of culture, is wholly and entirely a product of society. The great mass of peculiar phenomena, which owe their origin to the life of man in society, form a whole which is quite separate from the domain of natural life, and which is in a high degree worthy of separate observation and analysis.

Certainly it would argue a one-sided perception to seek for the process of association only among men. Tendencies to associated life are to be found in the whole of the rest of the world of nature. Indeed, even the minerals offer, in the special forms of many crystallising substances, the first dim gropings after associated existence. As the evolution of life goes on, association and its action meet us plainly in the vegetable world. Not as isolated individuals, but in what is really an associated state, does each single species of plant, carry on the struggle for existence. What else are forests and woods, than a special kind of society, composed of greater and smaller vegetables? Finally the associations composed of animals, are too obvious to require special mention. As is well known, a life in close communion, and carried on by a greater or smaller associated group, characterises a large number of the animal species, both of the superior and inferior kinds.

And yet, we at once perceive essential distinctions existing among them, when we compare human society with such associations as exist elsewhere in nature. Human society is capable of constant development; it has a history which is unbroken and is added to day by day. Every society existing elsewhere, in the region of purely natural life, is without a history; it takes place now as it did thousands of years ago, whether the example is that of the crystallisations arising from the evaporation of a free salt, or of the life in common of a swarm of processional caterpillars, or of a herd of buffaloes. And if anywhere among these purely physical communities of plants or animals, a trace of historical development is observable, we find that it is due to the influence of man. The mode and manner in which the plants which are useful to us, cover our fields in suitable combination, and in which the domestic animals live together, certainly shows a historical development. But this is a history which has been made, not by the plants and animals, but by men, who take both into their service.

Every phase of the history of the development of organisms, 
which Darwinism brings forward as a hypothesis, remains, in any case, quite unsuited for comparison with the constantly and uniformly progressive and never-resting history of the human race. In comparison with this, even if the existence of these phases of development is destined to be raised from a more or less vague probability to the rank of scientific certainty, they are nothing else than physical processes, similar to those changes which have been taking place in the star-systems during thousands of years.

The result then, so far, is that we once more find in human society an independent region of peculiar circumstances and phenomena. But this ought not to hinder us from adding the admission, that, without doubt, countless relations exist between nature and society.

Human society is influenced in a high degree by nature. The latitude in which a man lives, and the blood which flows in his veins, determine the essential character of his qualities, in so far as he is considered, not as an individual, but as a part of society. And vice versâ, human society exerts its transforming influence on nature. Nothing lies more obviously plain to unbiassed observation than this. Let anyone merely compare in thought the present appearance of the portion of the earth which is now covered by the city of London, with the wild aspect of the same tract of country, previous to its occupation by a community of men. It suffices too, to contrast a well-cultivated district in Germany or France, with an ancient American forest, to gain an overwhelming impression of the alteration of the earth's surface produced by human society. He who looks down from the charming heights which rise gently above the Etschthal near Roveredo, upon the luxuriant valley, with its manifold cultivation, its dozens of villages, and hundreds of country houses, and then perhaps calls to mind the forest wastes which exist in the interior of Russia, will comprehend what a deep impression human society may make on nature.

This very action and reaction, occurring between nature and human society, is fitted to arouse an interest in the great region of inquiry which the latter offers to us. If the saying, that "what"ever exists is worth becoming known," holds good of any matter at all, it is true of social life. We proceed to inquire next, what modes of investigating human society are open to us.

If we make a survey of the studies which make up the totality of human knowledge, we shall find that the social man and his operations have been since ancient times, and in the most various ways, the object of eager investigation to the learned. We may almost say that the peculiar actions and qualities of the social man have occupied the thinkers of the different nations much earlier, and to a much greater extent, than the facts and phenomena of the pure natural sciences. The spirit of man seems formerly to have 
cared far more to be busied with itself than with the objects of external nature.

First of all, we have philosophy. She desires to grasp and analyse the spirit of man in the abstract. But in this she deludes herself. That which she seeks she cannot find, for this spirit in the abstract does not exist. Spiritual life is developed first in society. Whoever approaches this matter in any mode whatever, whether it be by the more insecure method of deduction, or by the more laborious but less uncertain method of induction, never studies the abstract man, who does not exist at all, but merely man in a state of society.

Certain studies which assist inquiry into society, and which scientifically analyse certain isolated results of social life, are even more suitable for recognition than philosophy. What else can be claimed by the true science of theology, which raises itself above the mere collecting and handling of the dogmas of a single sect, than a set of investigations regarding the peculiar intuitions which have been produced, with their diversities as regards time and place, by the homogeneity of feeling in religious matters, which has grown up in society? In human life there is a strong tendency to mysticism, which seems only to meet with permanent and complete satisfaction by means of union to form religious associations. These, like the mass of religious conceptions on which they rest, are an unequivocal image of human society. Whoever busies himself with them, subjects to analysis an important, and for human civilisation, a highly characteristic form of the phenomena of social life.

If in human society at large, men have been principally led towards separate religious sects by internal psychical tendencies, it was chiefly the external needs of a peaceful and secure life, especially the need of security for person and property, which led to the growth of the idea of justice and the rise of political communities. Justice and law are conceptions which are quite strange to the isolated man above alluded to. As soon as an association of men comes into existence, the sphere of the power of the individual must be contracted. And therein we have the commencement of the development of the idea of right. It was not by a direct leap that mankind passed from this idea to our modern law-books, with their numberless paragraphs, but by a gradually ascending series of steps, consisting of the stages of development of this phenomenon of social life. The science of law, then, joins in working at the general problem of the investigation of social life. In so far as it inspires legislation, it may, in addition, gain an immediate practical influence on the regulation of this social life.

The productive activity of man, no less than life on a basis of law, seems to be peculiarly a product of society. Only a few have 
realised how much they rely on the widely-extended co-operation of society in the ordinary provision for the daily needs of life. In a highly-developed state of civilisation, for instance, among the population of a capital, it is an unimportant exception for one man out of the hundreds of thousands who labour and produce daily, to apply any at all considerable part of what he produces to the satisfaction of his own wants. He gives almost all he produces to the community, and takes almost all he requires from it in other goods. And the whole of this thousandfold exchange, of which money and credit are the powerful promoters, goes on, as a rule, smoothly and noiselessly, and not in consequence of legal ordinances, nor in consequence of sentimental love of one's neighbour, but entirely through the force of well-calculated egoism. Human society attains its highest triumph in the economic arrangements of life; here it shows itself in the plainest way as possessing a capacity for production, contrasted with which isolated human existence seems like mere impotence. Without the co-operation of society the very strongest man-the man who is most richly endowed with external aids to existence and action-is powerless. In the social state, the poorest man may have at his disposal, by the most insignificant expenditure, numberless men and natural forces. Does the dweller in Königsberg, who has sent a letter to Ala for a groschen, consider what a huge expenditure of capital and labour, ranging from the service of the postmen to that of the engineers who superintended the construction of the Brenner line, was necessary, in order to fulfil his desire so cheaply? And could we mention any greater example of what society performs for the economic interests of man, than the postal arrangements for the whole world? Economic science, then, devotes its whole force to the scientific investigation of a particular branch of social activity.

Great as is the magnitude of our formal judicial system, and marvellously as the free development of egoism acts in our economic system, yet even these are not sufficient to satisfy the wants of human society. Society demands that the State, and the communities which co-exist with it, for instance, the communes, should specially undertake the charge of the interests of society, and interfere here and there, partly to remove obstacles, partly to promote these interests directly. Politics is the name given to the contents of this complete sphere of activity, which superintends private affairs and the judicial system. Politics, too, has grown up from out of the interests of social life, and a scientific investigation devoted to it is doubtless an inquiry into a class of social phenomena.

The science of history should also be remembered. It evidently busies itself with the study of human society considered in regard to its development in time, and its grouping into States and peoples. 
Hence it has, pre-eminently, to deal with the most pregnant phenomena of political and national life. History cannot claim as its exclusive field of observation any particular sharply-defined set of facts, such as those considered by the science of law or of economy. It seizes, now on this, now on that, phenomenon, it attends now to the religious or the legal, now to the economic or the political division, according as one or the other is characteristic of a people or a period. It has been said (by Rümelin), and not untruly, that history, if it desire to give the characteristics of complete periods, States, and peoples, must, with more or less tact and accuracy, treat particular persons and facts as typical, although there is a contradiction in treating what is merely prominent as typical.

The work of all the branches of study which have been mentioned above, is evidently to elucidate and explain single classes of the phenomena of social life; but they are not concerned with the scientific analysis of human society itself, or with the explanation of the subjection to settled order and law, which to a large extent underlies it. That society is an object of scientific cognition has only been discovered in modern times. It is only possible, indeed, by means of a system of exact observation of aggregates of the facts of social life. The value of exact observation has only become generally known concurrently with the modern development of the physical sciences. Only an age which was ripe for exact physical investigation could witness the establishment of exact social investigation on the basis of a system of observation of aggregates in number and proportion. It is easy to anderstand that the systematic observation of aggregates of phenomena has a far higher value in the attempt to attain to a knowledge of the social life than in the physical sciences, and even that it should become of an exclusive importance in the former. Society is itself nothing but an aggregate phenomenon, whose laws, for that very reason, can only be discovered by means of the observation of aggregates. While the most important qualities discovered by the physical sciences can be predicated of the unit with the utmost confidence, the individual man, although he is a portion of society, is in no respect a correct representation of the typical social man. The latter can only be obtained by the aggregate-observation of thousands and millions, and cannot be discovered in the person of any actually existing individual. That which really is a part of the social man, will likewise take its place in the acts of the social man, and with those permanent results of these acts, which are also accessible by observation.

This system, namely, quantitative aggregate-observation, forms the essence, and the problem, of the modern branch of knowledge which we call statistics. Hence statistics appear as the scientific 
means for the investigation of the peculiar nature of human society, which must be grasped numerically, and in the aggregate ; and also for the establishing of the rule of law in social life.

In this work it will be shown how far statistics have already solved this problem, and what is to be expected from their further development. But first it is incumbent on us to make ourselves familiar with the aggregates which have helped us to conquer this new region of knowledge, and of which a still more extended use will be possible in future. This introduction, explaining the peculiar character of statistical inquiry, seems to me to be no mere by-work, but one of the most essential objects of the present work. It is evidently of far less importance, that the statistical materials, which exist among the various aspects society presents, should be placed before the reader in their full details, than that his interest should be aroused in statistical inquiry as such. But this object requires first an examination of the essence and method of statistics.

\section{I.-Statistics as the Means of Acquiring a Knowledge of the Laws which Regulate Social Life. Its Nature, Problem, Method, and Mode of Exposition.}

Few sciences have been defined in so many and so various ways as statistics, although it is one of the more modern subjects of study. It would be inconsistent with the object of this work, were I to offer the reader an enumeration and criticism of the dozens of proposed definitions. Only a few general remarks, therefore, can be devoted to the special fact of the excessive number of definitions of statistics.

This phenomenon will be understood, when we remember that various kinds of statistical inquiry had existed long before the expression "statistics" was invented. Professor Achenwall of Göttingen, the first writer to employ this word, about the middle of the last century, named his collection of so-called noteworthy political matters, statistics. As a matter of fact, the exact observation of aggregates, had only a very modest part assigned to it in the material of Achenwall's Statistics. This latter consisted chiefly of a collection of notices regarding the condition of States and peoples, pretty much resembling those we find in a school geography, or under the heads of the names of the principal countries in a conversation book. On the other hand, long before Achenwall, there had been, particularly in England, many exact observations of the circumstances of populations, in regard especially to mortality, partly carried out through pure scientific interest, partly for practical purposes connected with insurance. The first scientifically valuable treatise on these observations of the state of population which appeared in Germany, was the classical work of Süssmilch, the first edition of which was printed in 1741. It bore the charac- 
teristic title "The Divine Order in the Changes occurring in the "Human Race, proved by means of the Births, Deaths, and Propa"gation of Mankind." These inquiries, which were not designated in the last century as statistical, but were usually considered as belonging to political arithmetic, are far more allied to modern sta. tistics than were the original works of Achenwall. The Science of Statistics then, as a scientific conception, has experienced some changes during its history, by which fact the great number of its definitions is to a large extent explained.

In addition to this, there is further the fact, that, even at the present day, people use the word statistics sometimes in a wide, sometimes in a narrow sense. The first is the case when we speak generally of the Statistical Method of scientific inquiry; the latter, when the subject of discussion is the more contracted field of the independent Science of Statistics. The "statistical method" is not confined to the treatment of society; it holds a place in the observation and scientific use of purely physical facts. We may indeed include under the head of statistics in the wider sense, i.e., under the head of statistical method, all determination and grouping of facts which rest on the quantitative olservation of aggregates. The well-arranged returns as to temperature, rainfall, direction of wind, quantity of ozone in the air, which we obtain from meteorological stations, and which, for their sufficient exposition, require numbers and ratios, are obtained by the statistical method, in the very same sense as are the constant returns of births, marriages, and deaths, of the prices of commodities, and of the crimes committed and punished.

It does not at all contribute to the clearness of our insight into the nature of statistics, that statistics, and the statistical method should be spoken of in so vague a way. Hence it has with reason been proposed to speak in such cases as the above, not of the statistical but of the numerical method. But it will be hard to resist the prevailing usage with success, and therefore, for a long time, we shall probably hear the phrase "statistical method" employed in a general sense, and by no means confined to the independent realm of statistics.

The observation of purely physical facts, which haye no connection with the social life of men, is excluded from the field of the independent science of statistics. While the statistical, or numerical, method holds sway, wherever there occurs a quantitative determination and co-ordination of facts, based on observation of aggregates, the field of the science of statistics is restricted to the quantitative investigation of the social life of man, which is only attainable by means of the observation of aggregates. Accordingly, I may define the statistical science as the systematic statement and 
explanation of actual events, and of the laws of man's social life that may be deduced from these, on the basis of the Quantitative Observation of Aggregates.

At tirst sight it may surprise us that the quantitative observation of social aggregates should constitute an independent department of knowledge, while the same claim is not recognised in the case of the observation of purely physical aggregates. Why, it may be asked, should we in one group of aggregate-observations speak of an independent science, in another merely of a method?

One fact, which serves to answer this question, has been already slightly touched on in the introduction. But the question itself. which concerns the very right of the statistical science to exist, is important enough to deserve that in this place a complete reply should be made to it.

In the department of the physical phenomena which exist apart from social life, the scientific collection and co-ordination of facts, and their employment in quantitative aggregate-observation, and therefore the result of the application of the numerical method, belong not to a new independent science, but to the already constituted physical sciences. These certainly combine, in many cases, quantitative aggregate-observation with qualitative and quantitative unit-observations of the objects which lie within the province of their inquiry. But the definite fact remains, that the physical sciences strive to solve the majority of their problems by the latter methods of inquiry, which are entirely opposed to the statistical method, and that they employ quantitative aggregate-observation not as their exclusive method, not even as their primary method, but only as an auxiliary instrument of inquiry, The marvellous advantages of experiment for the establishment and extension of a scientific knowledge of physics, consist peculiarly in the contriving of particular unit-observations, which observations are at our option, are caused by us, and are accompanied by all the guarantees of exact investigation. It is quite otherwise with the observation of social facts. Here the laws of society cannot be discovered through qualitative and quantitative unit-observation, but only through quantitative aggregate-observation. Society is not a single individual, accessible as such to unit-observation, but a whole, composed of individuals. He who would gain a scientific knowledge of this whole must seek to extend his observations to all, or at least to as many as possible, aggregates of individuals, to their actions, and also to the effects of these actions.

The ideally best method of inquiry would therefore be the totality-observation of every single individual fact. Human imperfection, however, does not admit of our defining the totalityobservation of all mankind as the true principle of statistics.

VOL. XLVI. PART III. 
What is necessary rather than this, is to give up collective observation, and rest content with aggregate-observation. Not even the simplest social facts can be determined for all the human race, either now or for hundreds of years past. Nevertheless so much of the ideal principle of statistics remains, that, coeteris paribus, aggregate-observations give us better statistics the more they approach to totality-observation.

The sum of those social facts which can only be determined in their importance for society through quantitative aggregate-observation, forms the subject-matter of the special science which we call statistics. The difference between the peculiar methods of observation of this statistical science and the physical sciences is so important, that we are justified in making them plainer by the following remarks.

In order to determine the essential physical peculiarities of any species of plant, for instance, the Anemone nemorosa, it suffices to observe single perfect specimens of this species in the various stages of its development. The observations will in this case be partly qualitative, by ascertaining and noting down its peculiarities; partly also, quantitative in number and proportion; for instance, by the determination of its stamens, of its chemical constitution, in percentages of the separate elements : but they will always be unit, or individual, observations. It is still an observation of this class, even when more examples of the anemone in question, instead of one, are examined, with the view of checking and guaranteeing the observation. We could only speak of an approximate aggregateobservation if we desired to ascertain the geographical diffusion of the Anemone nemorosa, that is, to ascertain a circumstance of its social existence. Such an inquiry, however, in spite of its interest, is only of secondary importance. At all events, no one would assert, that the Anemone nemorosa could not be exhaustively treated by physical science, without a knowledge of its geographical relation.

Man also is treated, by anatomists and physiologists, on the basis of unit-observation, as an object of physical inquiry. No anatomist would require to dissect all, or even millions of men, in order to judge of the nature of the human skeleton, or of the muscular or nervous system, and in this way obtain scientific results.

If, however, man is to be scientifically investigated as a unit of society, the aggregate-observation of statistics is required. In order to obtain information regarding the mean duration of life, the inclination for marriage, or the tendency to theft, existing within a given social group, it is not enough to observe one individual until his death, but all individuals that exist in this social group, must be subjected to continuous aggregate-observation by means of statistics. If we were to actually observe one individual with regard 
to these social phenomena, we should soon discover to how small an extent he supplies the type of these phenomena. The individual would certainly die, but, in all probability, at almost any age except the mean age; very likely he would not marry at all; and, let us hope, he would not steal at all, either.

When the operation is concerned with the laws of social life, quantitative aggregate-observation is not a secondary, or to some extent, supplementary method, but the only possible mode of investigation. This is the deeper reason why the quantitative aggregateobservation of social facts offers to us, in the science of statistics, an independent, well defined, and rich department of knowledge.

In the above definition of statistics, there was no mention of the State. This may perhaps surprise many rtzders; for the illustrious originator of the modern scientific tendency of statistics, the Belgian Quetelet himself, who, more than any of his predecessors, desired to conceive of statistics as the exact social science, murked out its problem, as "The representation of a State at a given point of time." In this is perceptible, on the one hand, Achenwall's obsolete conception of statistics as a collection of remarkable facts concerning a State, and on the other hand, an inadequate comprehension of the whole extent of the domain of the social sciences, of which the political sciences form only a part. A clear insight had not yet been attained into the nature of society and its various phenomena, and statistics were consequently looked upon as an auxiliary instrument of that very important, but by no means exclusively important, kind of phenomenon, the State.

In view of the present position of the science, the limitation of the subject-matter of statistics to the description of the political circumstances of a country, must be considered as an obsolete and untenable point of view. Nevertheless, it must be admitted that the relations between statistics and States are many and intimate.

Such relations arise principally because the State itself is, as has been already remarked, a phenomenon, and, indeed, the most important and most obviously perceptible phenomenon, of social life. All "political" facts, which are suited for quantitative aggregate-observation, form on that ground objects for statistical inquiry. In this case the problem of statistics seems not merely externally but essentially marked off in accordance with the special departments of the State. Such is the case when the subjects for examination are statistics of the finances, or of the elections of representatives of the people in a particular country.

In addition, it is to be observed that some facts which in themselves, and as social facts, have a purely human character, first become capable of being observed, and accessible to the comprehen- 
sion of statistics, through the peculiar interest which the State takes in them, and the concrete character which it impresses on them as political facts. Statistics of immorality can never exist as such. Even the greatest enthusiasts for statistics would give up all hope of collecting materials for such statistics by interrogating their average man as to his course of life, and especially on his evil deeds. On the other hand, statistics of criminality do exist. That isolated fact which, as mere immorality, would have escaped statistics, can be grasped as soon as it appears with the concrete impress of an infraction of the State's laws, and thus becomes known. Here, then, it is the branding of a determinate human act by the State, which renders possible its entrance into the field of observation of statistics. Further, in the case of well-established violations of the law, the State renders to statistics a priceless service, by its careful search for the perpetrator, and its ample qualification of the deed in the verdict. The same is true of the law-giver, who, in the penal code, carries out a classification of crime which is highly important for the statistics of morality. In all such cases where the concrete character given to the facts by the State is of peculiar importance for their inclusion in statistics, the scientific operation in which this material is employed will usually take into account the boundaries of the State. This will be particularly the case if, as in the matter of crime, the character thus made clear varies more or less in each separate district of the State.

One important common relation between statistics and the State consists in this-that the most notable and the most comprehensive aggregate-observations of statistics would usually be quite impossible to perform, even in cases where political facts are not primarily in question, without the assistance of the authority of the State, and the thousandfold ramifications of its administrative organs. How could a census, in taking which the collectors should perform their work in every district of the country in one day, be effected without the State taking a direct share in its management? Who could rely on constant and regularly compiled reports of births and deaths, if the State did not take over the collection of these data from the registrars of the civil State, or the parish registrars? This necessity for obtaining the fullest assistance of the State in making arrangements for the most important collections of statistics, has led to the rise of official statistics, the organisation of which will be specially treated of further on. In these cases, of course, it is only the collection and grouping of the facts by the servants of the State that is official in relation to the statistics, and not the further scientific work which must be done in order to make use of the official numerical materials. In relation to the scientific work which depends on the official numerical materials, nothing is more natural than that, while making use of 
the material collected on the same plan in all parts of the dominions of the State, the process should as a rule be limited by reference to the districts of the State. From the scientific point of view, however, there is nothing to debar statistical inquiry from over$r$ tepping the frontiers of the State. Indeed it is desirable that this should be done to some extent in regard to all social facts which possess a purely human character (as, for example, deaths and births), and which we meet with in a state of classification according to political boundaries, merely in consequence of the inability of the servants of the State in those early times to collect facts outside those boundaries. Evidently, in such cases, it might be much better to found a comparative inquiry on geographical than on political differences. Assuredly it is better to investigate separately the mortality of the Alpine region, the Suabian-Bavarian table-land, the Böhmerwald, the chain of the Jura, the plateau district, the Rhenish flat country, and so on, than merely to determine the general mortality of Bavaria, of Würtemberg, of Baden, and of Hesse.

The so-called geographical method of statistics renders it possible to combine a regard for that which the political method of collecting the materials requires, with the satisfaction of the demand that the most important statistical inquiries shall be freed from the trammels imposed on them by political boundaries. It is therefore necessary to supply a more detailed explanation of this method.

A great deal of the scientific worth which modern statistics can claim for themselves, they owe to the reforming influence which the investigation of the "laws of large numbers" has had on the older incoherent and scientifically defective collections of notes, to which the name of statistics was given. It has been discovered, that definite conformity to rule and law cannot be traced by means of isolated observations of actual facts, while by means of statistical aggregate-observation of these facts, these conformities become perfectly evident. Süssmilch worked on this plan in Germany, more than a hundred years ago, and later during the present century, it has produced splendid results, in the hands of the Belgian Quetelet. Statistical science thus directed, strives in all cases to obtain averages from the largest possible number of observations, and finally to arrive by calculation at the average man. The actually observed differences of phenomena, in relation to time and place, are treated as more or less extensive variations from a Type, which is represented by the grand average thus obtained, and to which they are subordinate in importance. This conception of statistics would find its highest aim attained, could it, year by year, treat unhindered the whole earth as a field of observation, and make in it 
a uniform set of investigations, and from milliards of facts obtain the grand average of the world.

It is impossible to mistake the strong influence which this conception has had on modern statistics. Nevertheless, there prevails a feeling, that the whole of the results which may be expected from statistics, cannot be attained merely by means of the "average man," and especially not by grand averages alone.

Certainly the grand average, in which differences of time and place are reduced to zero, possesses its peculiar worth. It is the shortest and most general expression of the compensations which act, through the juxtaposition of millions of observations of facts, on the differences of time and place, to produce one single unit of investigation. Such an abstraction as this is easy to handle; it supplies a first general view of the probable state of things. Much which, in the multiplicity of phenomena, influences and distorts their broad outlines, vanishes before this, so to speak, telescopic inspection.

This grand statistical average, which ignores time and place, is authorised, and its: nature made evident, at the commencement of modern scientific statistics. Simultaneously with these authorised inquiries into grand averages, there arises a further, not less important and sometimes much more comprehensive process, namely, the scientifically exact conception of the differences in the phenomena of the social state, in relation to place and time. This problem essentially varies in character, according as the differences are those of time or of place. It is simpler in the case of differences of time, more complex in that of differences of place.

The further examination of the question how best to employ scientifically differences of statistical results in regard to place, leads to the "geographical method" of statisties.

The divisions of time into which statistical observations are analysed are partly supplied by nature itself-such are the year and the day; partly by widely recognised customs-such are the week and the hour. Hence the complete similarity of its divisions of time, from the earliest ages, is, with a few exceptions, secured to comparative statistics. This gives differences of time a high importance, and a special scientific value in statistical observations.

Opposed to these are the dixisions in space which usually form the basis of comparative statistical inquiries, and which are entirely dissimilar and arbitrary.

Comparative statistics usually effect their calculations by means of average results for whole countries, or, at the best, for large constituent parts of these which have been fixed on by administrative arrangement. Clearly this mode of comparison does not correspond to the more profound requirements of science, because the various 
countries and provinces are of very different sizes, and because, in average results for whole countries and provinces, the very heterogeneous circumstances of the smaller tracts of country become obliterated, thus producing a collective expression which is only accurate in appearance. Even in this case the grand average has ouly the value of a first general approximation, which must be followed by the more accurate conception which includes the differences in place. The grand average for whole countries and provinces does not satisfy this need for an exact comprehension of the differences in place of the circumstances and phenomena observed by statistics. And here the geographical method is of use, which method explains the effect of the peculiar geographical formation of the natural districts, in regard to the statistical circumstances in question.

For this purpose it is necessary that the statistical processes of Observation and Treatment of the material should be confined to small sections of country, the lower limit of whose size is only defined by the necessity of procuring a number of observations sufficiently great to produce an average result. We thus obtain the statistical results for these small sections, and, by juxtaposition of equal or similar results, we get the natural districts corresponding to the concrete facts. The groups are in this manner discovered, and have an altogether different geographical appearance, and a totally different system of boundaries from the States or provinces.

Every branch of statistics which rests on the observation of facts differing as to place, has its special geography, of which averages obtained from whole countries and provinces can only present a caricature. The boundaries of the natural groups supplied by a social phenomenon, and those of the chief political divisions of a country, intersect each other at so many points, that if our consideration is confined to the latter, all profound scrutiny of such phenomena comes to nothing.

The geographical method of statisties shows itself peculiarly effective, if it is applied for the purpose of comparison, in such a way, that the natural districts are determined with reference to one phenomenon alone, which phenomenon is to be compared with the others, and then all the remaining phenomena are classified as regards place, according to the groups and districts thus determined. For instance, if it were desired to compare the infant mortality with the number of births, with the frequency of illegitimate births, and of still-births, and with the density of population, we should first determine the natural districts of the various grades of infant mortality, and then calculate, for these districts, all the remaining statistical circumstances which are to be included in the comparison. These groupings of the materials carried out for the purpose of comparison 
constitute the experiments of statistics. By their means, in many cases, are we for the first time enabled to see whether the relations between different phenomena, which relations perhaps appear, on a general superficial comparison, to exist, have any actual reality. No general assertion can be made as to how large, or more accurately, how small the geographical sections should be, on the geographical method. Perhaps it is best expressed by saying that they should be as small as possible. With reference to the latter consideration, the condition that there should be a considerable mass of observations, supplies, as has been already remarked, a lower limit. The necessity that the mechanical work of reckoning should admit of being performed without excessive labour, acts in the same direction. If, for instance, we desire to calculate for Bavaria any statistical fact, such as the infant mortality just mentioned, and were to base our calculation on the parishes instead of the administrative districts, we should have to perform, in round numbers, 8,000 instead of 180 operations; not to mention that, in the case of the smaller parishes, in order to obtain aggregate observations we should have to trace the returns back through a long series of years.

The inferior limits of the sections, therefore, determine themselves according to the nature of the special problem, and cannot be laid down once for all. For the general facts regarding population, the treatment of which, on the geographical method, seems particularly desirable, sections of about Io square miles (250 square miles English) might suffice for the circumstances of Central Europe. The applicability of the geographical method entirely depends in practice on the utilisation of small administrative districts, for which there already exist statistical compilations. If, for instance, the construction of natural districts is to follow from the statistical results obtained from smaller divisions, such as parishes or even villages, the elementary numerical work which is required for the mode of formation of the statistical geography alluded to, by means of a vast number of separate observations, will in almost all cases be impracticable.

With the geographical method of statistical inquiry is connected the eartographic representation of the results of investigation. At present we cannot examine this subject closely. The explanation of the modes of exposition employed by statistics, will subsequently lead us to a more detailed description of the nature and value of statistical cartograms.

The collective whole of the operations which make up the essence of statistical inquiry, may be divided into the following three groups :-

1. The aggregate-observation of the social facts. 
2. The grouping and numerical treatment of the original statistical material obtained by this aggregate-observation.

3. The further scientific employment of the numerical materials of statistics, especially with a view to the establishment of the existence of regularities in social life.

The aggregate-observation of social facts forms the first step in statistical operations. The material for this process is unlimited; for every day brings into existence thousands of millions of new social facts. It is evident that all these millions of facts cannot for the purposes of statistics be observed and fixed, by entry in lists for further treatment. To this end such an amount of labour would be necessary, that mankind would be disturbed in the performance of the most important duties of life, by such an extension of statistical observation. In point of fact, under the head of "social facts," in the widest sense of the phrase, there are such an enormous number which are more or less indifferent as regards the information they supply as to social life, that an extension of observation to them would seem to be mere waste of human labour. On the other hand, there are also many social facts which are not altogether indifferent in the sense specified, but which are of such a nature that the trouble of observing them either bears no proportion to the value of the result to be expected, or else would be so gigantic as to be absolutely inadmissible. Let us imagine, for instance, that, for the whole people, the task is proposed of determining daily, as regards each individual, how much time is spent asleep and awake, eating and drinking, working and resting, stauding, moving or sitting, and so on. Certainly a concrete solution of this problem would be a statistical curiosity of the first rank; but it is equally certain that no means can ever be found which could render possible the carrying out of such an investigation. But if statistical enthusiasm were to go further and demand an answer as to whether sleepers lie on their backs or on their sides, and whether they lunched at 12 or 1 o'clock, it might justly be said, that, though not altogether indifferent, such questions were open to the sound objection of being comparatively of small relevancy.

Of the great mass, therefore, of social facts of all kinds, only insignificant portions can be subjected to statistical observation. Moreover, the choice of the subjects of observation must not, of course, be made at random, but must above all things be made with regard to the import of the facts viewed as supplying information concerning social life.

It will certainly happen, in single cases, that facts of inferior moment will be noted, while others of more importance are disregarded. Such is the case, if other interests than those of sta- 
tistics merely, for instance, those attaching to police regulations, require the determination of some fact of small importance socially, and if the material, when once obtained, is, for this sole reason, made use of by statistics.

So far the sphere of the facts which are capable of aggregateobservation is already extremely contracted; but the limits of observation are not even yet completely assigned. It is not possible, in the case of all the materials which are actually available for statistical observation, to devote unrestricted attention to all the real varieties among the single facts. Statistics seize on and level with a somewhat rough hand, many points of difference in the details of the separate phenomena, and only consider those qualitative differences in the subject of their observation, which can be firmly grasped. The statistics of marriage will assuredly not be content with a bare return of the number of marriages, but will draw distinctions, for instance, as to age and profession, religion, civil condition of the parties to the marriage; but will not give expression to the romantic or prosaic details of the motives to marriage, and the previous history of each separate couple.

If we inquire further as to the reasons which lead, in statistical observations, to the neglect of those qualitative differences in observed facts which are actually obtainable, we shall find that they are of two kinds. Such qualitative differences remain unnoticed, either because they cannot be quantitatively determined at all, and, therefore, are at the outset removed from statistical inquiry, or else because, though not in themselves incapable of quantitative aggregate-observation, they, after a real examination, would not increase our knowledge of social life at all proportionately to the labour applied. The same causes, then, which exclude numberless facts as such from statistical observation, enforce, in the case of others, a contraction of our attempt to comprehend their qualitative differences. In the case of a census, for instance, we should leave out of consideration the mental faculties of the population on the first, and the weight of the single individuals on the second, of the grounds here mentioned. Nevertheless, the opinions held by different persons and at different times, as to which of the different attributes of social facts that can be dealt with, are to be comprehended by statistics, are various. The censuses of to-day include much special information concerning the persons counted, which was not thought of half-a-century ago. In like manner the censuses of the future will probably put many questions which people at present are ashamed to ask. Even now a great difference is observable in the reception granted to statistical curiosity, according to the circumstances under which the returns are made. In the case of a general census, we are very cantious in 
putting somatological questions, for instance, as to size, girth of chest, colour of eyes or hair, and of complexion; but we are by no means shy of asking such questions in statistics for actuarial pur. poses. We also find that the State is much more free to deal with persons liable for military service, even for statistical purposes, than with the persons to be counted in a census.

However far the collection of qualitative differences hitherto neglected may go, as the interest in statistics increases, these differences will never be completely observed. The defective side of all statistical inquiry, will always lie in the difficulty, when combining numerically observed facts, of so treating all the real differences of the phenomena to be determined, that nothing but similar units shall be included in the totality obtained. As a rule the multiplicity of the phenomena is so great, that the hope for complete similarity of the facts to be numerically combined in any statistical result must be altogether renounced. It is important to discover the proper point of view, from which the observer may lose sight of a sufficient number of qualitative differences in the observed facts, in order to effect the synthesis of the latter, which will then form one apparently homogeneous fact. An observer who adheres too closely to the details of the phenomenon examined, can never obtain a complete view of it; and he who desiring. to obtain this complete view, remains so far off that he can no longer distinguish the light and shade in it, will obtain nothing but a, general knowledge of the facts, which will warrant him in drawing few conclusions. In the first case, the observation will suffer from all the faults of short-sighted persons, who can well distinguish what is near, but fail to discern objects at a distance. In the second case, the error of the long-sighted man is apparent, who overlooks the details of an object situated near to the eye, and merely obtains a view, which is very clear and correct, but is deficient in details. The statist is always in danger of being too far-sighted; the so-called "practical man of experience," who lonks only at isolated eases, runs the risk of becoming short-sighted. Hence they disagree as easily as a short-sighted person with one of long sight, who cannot understand why the former fails to distinguish the figures on a church clock.

Statistics do not supply genre pictures of social life. Their work is of a totally different character. They give a picture of the circumstances of social life in large and characteristic lines, on the basis of a multitude of observations, which are freed from the special character of any one point of view. The more or less subordinate details, which have no place in company with the marked features of the statistical picture, may well be given up for the sake of the great advantage which is to be found in dealing with large numbers of observations, and the guarantee these latter offer for 
unbiassed conclusions. The statistician alone can disclose the large features of social life, since he frees himself from the disturbing side issues which beset a study of the single facts. In this respect he is like the traveller who places himself at some distance from the Alps, in order that he may rightly perceive the configuration of the mountain chain. The traveller also, must give up all very minute distinctions between field and wood, meadow and pasture land, but instead of these, he, like the statistician, obtains a correct picture of the grand features of the mountain system, which quite escapes the notice of anyone who finds himself in immediate proximity to the mountains.

If we examine the process of statistical observation more closely, we find that it may either steadily follow the stream of social events, or else may take place at considerable intervals, with a view to the delineation of the circumstances of society at a particular moment of time. The constant registration of births, deaths, and marriages, of immigration and emigration, of the commission and punishment of crime, and so on, belongs to the first of these categories; a census, on the other hand, to the second. These latter are termed simply numerations, in contrast to those constant registrations of certain social facts which rather resemble book-keeping. Intermittent numerations become necessary in all cases where an unbroken succession of observations is impracticable on account of the magnitude of the material, as well as of the labour and expense required. It is impossible to renew daily or weekly our numeration of the population of a country, and therefore we must allow a long interval to elapse between one such operation and the next. The physiognomy of the population, which is to be obtained through these from time to time recurring photographic operations, will serve as regards essentials, to represent the interval during which this branch of statistics is not active.

We must note a further and highly important distinction in the nature of statistical observations, according as the facts to be ascertained are completed, as events, before the eyes of the observer, or whether their collection implies the questioning of a third party. Of the first kind are statistics of criminality, which take their material directly from the records of the criminal courts; while a census or statistics of industry belong to the second kind. If the interrogation of a third party is necessary, the possibility of relying on the original statistical material depends largely on the good-will of the person questioned, who only rarely has an immediate interest in the statistical operation, and often has a superstitious dread of it.

It is a noteworthy circumstance that by no means all the observations of facts which supply statistical material are carried out entirely or merely for the benefit of statistics. Long before a science of statistics existed, there were systematic determinations of 
social facts. There were, for instance, the ancient parish records, with their registers of marriages, baptisms, and burials. Even now the publication of marriages, births, and deaths in the civil register is treated as of high importance, not on statistical grounds, but chiefly in the interests of law and administration, though certainly the material collected from these motives is of the highest value to statistics. For the development of statistical science, this circumstance, that it found ready to its hand copious materials, previously collected for other reasons, which it could make the best use of, was of unusual importance. Had there been no parish records, the modern development of statistics of population could not have dated its origin from Süssmilch's work. The professional statist easily comes to be suspected, both by Government and people, of excessive curiosity; all the more desirable, then, is it, that other important reasons, besides the interests of statistics, should exist in favour of the systematic aggregate-observation of social facts. The German census could hardly have attained the development of which it can now boast, if it had not previously been necessary to obtain the numbers of the populations, in order to divide the customs revenues among the States of the Zollverein, and if the German Governments had not made inquiries into the magnitude of populations on certain public grounds, such as representation in the Reichstag, the peace strength of the army, and the assessment of the taxes. In these cases the statist is in the fortunate position of not having to propose an entirely new inquiry. It has been already granted on other grounds, and he has only to consider bow the existing registers of facts can be made use of by statistics in a suitable manner. At this opportunity it will not be difficult for him to urge successfully an increase of the contents of the registers, which will be very desirable in the interests of statistics, though not necessary for the immediate practical end of the inquiry. The census arrangements of Germany offer a gratifying instance of this, for they extend in statistical details far beyond the measure of what would be absolutely necessary for the exclusive carrying out of the orders of the Government.

When once the interest of the State has been aroused in the promotion of statistics in general, as well on their practical as on their purely scientific side, it is possible to obtain the institution of inquiries solely for the benefit of statistical objects, such as returns of agriculture, and of the results of harvests, of the number, nature, and extent of industrial pursuits, and so on. In these cases the statist who has obtained the inquiry has a freer choice as to the nature and extent of the determination of facts to be made than when the scope of the inquiry is already more or less marked out by other motives. 
In order that the determination of the facts may serve as a secure basis for further statistical operations, it is necessary that it should be correct in its totality, that is, complete and correct in regard to its individual parts; in other words, sufficient. There must be no deficiencies in the whole formed by the observed facts, and the observation itself must accurately determine each single fact. The completeness and sufficiency of the returns depend on many circumstances, some of which deserve mention here.

Above all, the nature of the arrangements made for the inquiry have great influence on the trustworthiness of the results. In any case, it is necessary that there should be a careful organisation of the machinery of inquiry, which in great statistical undertakings, for instance, in the modern census, embraces a very extensive region. Many thousands of enumerators must work at such an undertaking, and nothing which may concern the execution of their task should remain undecided. Whoever orders a statistical inquiry, ought therefore to think not merely of the scope and nature of tine results which he wishes finally to meet with in the actual tables, but he must, above all, have a clear idea of the conditions under which the collection of the statistical raw material can be made securely, and on a uniform plan. The way has been opened towards a comprehensive improvement in the methods of statistical inquiry, by the repeated conferences of the representatives of official statistics, which have been recently held expressly as a result of the statistical congresses.

Next in importance to the arrangements made for a statistical inquiry, comes the condition that these arrangements should be comprehended by those who are entrusted with their carrying out, and by the public, whose cordial sympathy and co-operation should be enlisted. Very often a failure is due not to a want of excellence and care in the arrangements, but rather to the state of mind of the agents in the inquiry, and the public, towards statistics. These agents are in most cases functionaries and public servants who, often overloaded with the other work of their calling, and only slightly instructed in the nature and meaning of statistics, consider the inquiry into the problems set them as an objectionable piece of labour, or even as the disagreeable outcome of an incomprehensible curiosity in the higher Government circles. And even when there is no want of good will, as is the case with the volunteer enumerators who take part in a modern census, the capacity of the agents may leave much to be desired. It is even worse as regards the public to whose interrogation the inquiry is directed. The public, as has already been remarked, has frequently a thoroughly superstitious fear regarding the questions asked for statistical reasons, or even considers them as impertinent attempts on the secrets of individuals. 
The peasant, who, for purely statistical objects, is questioned as to the produce of his grain cultivation, sees in this the forerunner of a rise in his taxes, and the lady of good society who is asked to give her age for entry in a census list, considers the question very impolite, and is not too conscientious in giving her answer.

Considerable improvement in this respect may be looked for, in the case both of the collectors and of those interrogated, from a wider extension of an insight into the nature and import of statistics. As it is, no one thinks any longer of promoting statistics by officious falsehoods, and still less will it ever be considered a glorious act to play statistics a trick by means of a safe lie.

The special intention of the statistical interrogation also has great influence on the earnestness and conscientiousness of the questioner and the questioned. For instance, we may conclude that the return of age in certificates of death will usually be more correct than in a census list. Before the coffin of the dead, many petty and frivolous motives cease to affect the members of the family, which may endanger the accuracy of the age return in the case of an enumeration of the living population.

Whether the returns asked for are to be constant, or are merely to recur at stated intervals, is of some importance as regards their probable accuracy. We may assume, that returns of the former kind are less laborious and disagreeable, both for the agents, and for those who are required to give information, than those statistical operations which only recur after long intervals. That births and deaths should have to be entered in a continuous register, displeases no one ; but it is more or less startling to many of those concerned, that the magnitude of the population should be obtained afresh every five or ten years.

The formal conditions on which the return is made are not unimportant. From this point of view, it seems desirable that the most important and greatest of statistical operations, such as a census, should be carried out in virtwe of laws. The absence of a basis of law will most likely foster the idea held by some people that they are the subjects of a sort of curiosity that is not quite justifiable. In fact the great statistical operations come in contact with the interests of the State and of the sphere of the life of the individual at so many points, that it seems highly desirable that there should be a legal basis for them, especially if they cannot unsupported extend their influence to all the multiplicity of detail connected with the technical part of the inquiry.

Even if all the conditions of a statistical return were to be as favourable as possible, the complete ideal of the aggregate observation of social facts will never be attained. For the very reason that we have to do with masses of observations mistakes in 
the returns are inevitable. If we were to have the popalation of a whole country, or a great city, counted simultaneously by different agents, the results of the different returns made would differ to some extent the one from the other. The figures of statistics do not express the absolute truth, do not express certainty, but only a degree of probability; in the case of good observation, indeed, a degree of probability which nearly approximates to certainty. Herein lies no weakness, but rather a strong point of statistics, which they have in common with the exact investigation of the physical sciences. Ignorant men to whom the nature of statistics is unknown and repugnant, imagine that they can show them to be worthless by producing as evidence a single inaccurate observation, which they boast of having themselves occasioned. The history of statistical science shows that it passes from such attacks to the order of the day, and that the childish or malicious lies of single individuals affect but little the totality of statistical results. But if anyone comes and proposes to consider statistics, on account of the errors of observation to which they are well known to be liable, as inferior to other branches of knowledge, which are supposed to be free from such errors, the answer that should be made is, that it is an idle dream to imagine that other systems, and in particular those which rest on speculation, are free from perturbation produced by erroneous observations and intuitions. It is in fact certain that human speculation is much more richly furnished with errors than are the numerical premises of statistics. The difference lies in this, that these errors escape becoming known and criticised, while statistical science does not deny its errors, but strives honourably to restrict more and more the limits of error.

A special technical theory of statistical aggregate-observation has been only constructed gradually, and, to a large extent only in modern times. This technical theory manifests itself specially in two directions; in the skilful management of the mode of putting questions, and in correctly placing the answer in a written list.

In the case of great statistical operations, the proper settlement as to what questions shall be put in connection with the whole organisation of the business of the inquiry, seems a very comprehensive task. Let us take a census, unquestionably the most important of all statistical inquiries, as an example. Who are to be enumerated ? The outsider replies, "the population." The statist objects, "but who are comprised in the population to be enume" rated?" And on further analysing this question, he shows, that the apparently simple conception implied by the word "population," is in reality complex, and that, in carrying out the business of enumeration, we must sufficiently determine whether the persons who are present at the place of enumeration at the time of the 
enumeration, or the persons who are residing in the place mentioned, are to be counted, or, again, whether all who have certain bonâ fide relations with such place, are to be counted. Having further decided when the enumeration is to take place, and what information concerning the individuals enumerated (such as name, age, religion, \&c.) are to be added, it is necessary to arrange for setting the work of enumeration on foot, and especially to obtain the large number of enumerators which is desirable for this purpose. The direction and carrying out of the system of statistical interrogation is therefore an important branch of the technical theory of statistics.

The best system of interrogation is of no use, unless care is also taken that the answers made may be correct, and placed in a form which is suitable to further statistical treatment.

This form can only be obtained in a written register.

The records which contain this registration we call a filled up form of return (Erhebungs Formular). The forms of return are either lists, or papers* (Zahlkarten). We have lists, when, in one record, many single facts, belonging to the statistical return in question, are registered in succession. A register of the civil State, in which the births are entered successively is, when considered as statistical raw material, a list. And the same of the householders' lists employed in a census, in which all the members of the household are entered one after the other.

Every form of return, on the other hand, which is devoted to a single observed fact alone, is called a paper. If for instance, a householders' list is divided into single documents, each of which only contains the information obtained regarding one individual, such a document is a paper. Papers have undeniably been used as forms of return much more frequently of recent years than formerly. It is impossible to state in general terms whether lists or papers are best; this depends on the special characteristics of the case.

The careful planning of the form of return is an achievement of the most recent development of statistics. Many old statistical returns struggle under the want of a distinction between forms of return, and forms of concentration. This is especially the case with the comprehensive returns, by means of which the various Governments, stimulated by Napoleon's example, strove to obtain $\Omega$ more complete knowledge of the conditions of their States and populations. The desire to procure as quickly as possible all they wanted to know, left no time for a careful determination of the method of inquiry. They were satisfied with specifying the nature of the grouping, in which the results of the return were finally to appear, without raising the question of the nature of the primary form of interrogation, that is, they devised forms of concentration,

$$
\text { * Or "cards." }
$$

VOL. XLVI. PART III. 
but no forms of return. The careful treatment of this latter important branch of statistics has been coming gradually to the front, down to the most recent times. The industrial statistics of the Zollverein are even now, in the seventh decade of the century, produced without the aid of a distinction between the form of return and the form of concentration. It is clear that such returns are greatly defective. The less we make plain to the agents of the inquiry, the road they ought to follow, especially if a correct and comparable net result is required, the less ought we to wonder if they miss this road.

Finally, it is worth while to consider the question who is to fill up the forms of return, the interrogator or the person interrogated. There are inquiries, in which, from the nature of the case, only the person interrogated can give a correct answer in writing. Among these are returns of financial statistics, which are required from savings banks, companies, school authorities, vestries, and so on. In such cases, answers given in writing by the persons questioned have long been the rule. In modern times, however, this plan has become usual even in cases which concern the whole population, and therefore in a census, the supplying of answers for the lists, or the papers, by the separate heads of households, is naturally the next step, whenever they can and will write. This system of "self "enumeration" has developed itself especially in the case of the German census.

The grouping and numerical treatment of the statistical raw material, obtained by aggregate-observation, forms the second step in the carrying out of statistical operations. The problem is so to use the material obtained by observation, in the form of registers, lists, and papers, that we may obtain a clear and easily understood picture of the individual facts, as determined, with regard to their specific qualitative differences, by that observation. The material obtained by a census, in the shape of householders' lists, with their register of the names of the members of the household, with the addition of their ages, professions, \&c., is as far from being the statistics of the population, as a heap of building stone from the quarry is from being a house.

This clear and comprehensible picture of the results of observation must, for the purposes of statistical inquiry be given in numbers: and the orderly summary of the numerical results obtained from the raw material are called "tables." In statistical tables, the material obtained must first be surveyed with regard to the absolute numbers it supplies. The orderly tabulation of the numerical material, therefore, precedes further labours of calculation, which are specially adapted to the evolution of what are called relative numbers. We may call the former primary, the latter secondary 
tables. For instance, a table showing the number of inhabitants in a province of a country, and the varieties of their religious beliefs, would be a primary table. If on the other hand there were another table in which was shown not the absolute number of the persons belonging to each religion, but the percentage of the population formed by each religious sect, this would be a secondary table.

We shall speak of the most important reckoning operations, which are performed on tables later. We shall now deal with statistical tables as such, and with the technical handling which is necessary for their construction from the original material.

Statistical tables contain a numerically accurately composed synthesis of the observed social facts. Synthesis and grouping of the observations are alike necessary at this stage of statistical operations. The raw material of statistics, as produced by the process of observation, consists of isolated determined cases, which have to be combined in accordance with the resemblances among the facts observed. The separate facts must be treated with regard to their observed qualitative differences among themselves, that is the tables must be sub-divided, even if the chief conclusion of the table can claim of a general and comprehensive nature without securing attention for the various qualitative differences which are included in the respective divisions. Supposing, e.g., we are dealing with statistics of the religious beliefs of a population. In this we go through the householders' list one by one, and place in a separate division of the table, the number of persons belonging to each sect. In addition to the results of these subdivisions of the table, we must indicate the total number of the population, without further considering qualitative differences with regard to belief.

If several qualitative differences are to be exhibited in one table, we get a composite statistical table. This is the case, when, for instance, the sex, professions, and religions of a population are exhibited in one table, without these three kinds of qualitative difference being combined with one another.

The subdivision of a statistical table is performed on two essentially different principles. It is either a grouping of the facts according to their special characteristics, i.e., a division of them according to their internal differences, or it is a grouping with regard to time and place, of simple facts, or perhaps of facts which have been subjected to internal combination. We have a grouping of the first kind, when the whole population of a country are distinguished according to age, sex, civil state, professions, \&c. On the other hand, when the births and deaths which occur in a country during the year, are distinguished according to the calendar months and the districts they occur in, we have a grouping of the second kind. 
Both modes of statistical grouping are of equal importance. It is evident that the grouping according to fundamental differences, is the first operation which brings with it the more profound knowledge which is necessary for statistics. We have already said all that is needful as to the importance of correct grouping with regard to place, while treating of the geographical method. It only remains therefore, to say a few words about grouping in time. This of course only takes place in the case of a constant series of observations of such social phenomena as are continuous, and not in the case of statistical pictures taken at a point of time, which, at all events in theory, do not extend in time at all. Whenever, a grouping in time occurs in statistics, it has this great advantage over a grouping in place, that divisions of time are well-known and are possessed of a similarity to one another, which is altogether wanting to the divisions in place. Districts $\mathrm{A}$ and $\mathrm{B}$ will always be portions of space which differ in character more or less, but the first and last day, and the second and third week of a year, are, respectively, perfectly similar divisions of time. Besides, for the civilised world, every day in the calendar, and every year in the calendar forms a well-known fact of the first rank, while a sufficient knowledge of any one of the space divisions which form the foundation of statistical observation, is only common in the narrowest circles, even when the subject in question is merely its superficial extent. It will be understood, that this being the case, comparative statistics work under more favourable circumstances in the matter of time than in that of place. Moreover, in the former case the perturbations are less. We have chiefly to remember the variety of calendars in use, and the unequal lengths of the months. But even these anomalies are well known, and can therefore be easily taken into account in statistical comparisons. This is, it is true, not always done even when it might be effected without any trouble. This is the case when the death-rate is calculated and comparisons made with reference to the calendar months without regard to their differences in length.

For the procuring of the raw material which is necessary to the attainment of the figures for a tabular statement, a special technical theory has been developed, for which we have chiefly to thank the statistical bureaux. The old method of converting the raw material into the tabular form, was that of employing strokes. It consists in this, that the table, with all its columns, is prepared on a large scale, and then each separate fact in succession is marked by a stroke in that column of the table which has the heading under which the fact in question comes. When all the material which is to compose the table has been gone through, the strokes in each division are counted and the totals thas obtained are subjoined. 
This method, however, is only available so long as the operation is either a mere primary process, or the construction of a table which contains no comprehensive statistical combinations, and therefore has only a small number of columns. But as soon as the columns and rows of a table become numerous, the employment of strokes is clearly a tiresome and also a highly untrustworthy method of treating the raw material of statistics. At the present day tables containing strokes constructed on a large scale, would be so very balky that they would cease to be manageable, and errors in finding the right column from among hundreds of such columns become more and more frequent. It should be remembered that the combinations that may be made among the age (by single years), sex, and civil state of the population would give about 800 columns of our table. If we reduce the classes of age to twenty, and add a set of 300 kinds of professions, which is by no means the limit of the details that might occur in statistics of professions, we get 48,000 rows. To find the right row from among these for each stroke on the plan of marking by strokes, is impossible without great expenditure of time and without making mistakes. Recently another method has been invented for such cases as this, namely, the treatment of the statistical raw material by means of leaflets. The technical theory of this method is briefly the following:-From the registers of facts which the inquiry supplies, the returns which are to be employed statistically, are extracted for each single fact, and entered on a separate leaflet of moderate size. These leaflets are then sorted into heaps according to the points of view which the grouping of the table that is to be constructed implies. When all the leaflets have been gone through, the heaps are counted and the numbers thus obtained are entered in the table. This method admits of the greatest multiplicity of statistical combinations without necessitating any proportionate trouble, since in the case of problems of an intricate character a division of labour is possible. After the preliminary distribation of the leaflets according to general differences, there may follow a further sorting process, carried out with a view to such differences of detail as it is necessary to note. The work of sorting can be materially lightened by fixing on different colours for important differences in the observed facts, such as sex and civil station in the case of a census.

If the inquiry has been made by means of papers, i.e., separate forms of return for each fact, these could be used for the primary process as leaflets, without further trouble. But in this case a certain amount of technical difficulty is produced by the circumstance that such papers are usually of much more considerable size than the leaflets would be, and that it is harder to make use of 
differences in colour on this plan, so long as their filling up is left to the public.

The peculiar process which is necessary to the production of well arranged tables, from the scattered lists of facts which form the raw material, and which, in the larger operations of statistics, almost resembles one of the manufactures, may be called the technical process of statistics. It appears in all statistical work. Such a process can only be carried out to any large extent by the employés of a statistical office. It has already been remarked, that the absolute necessity that the more important statistical inquiries should receive the fullest assistance from the authorities of the State, has led to the rise of official statistics. I may add that the same assistance is required for the technical treatment of the material, as for the procuring of the returns, as soon as the material in question becomes at all considerable.

A question now arises which is not unimportant in itself, and is of the highest interest as regards our knowledge of the modern development of official statistics. It is, whether the technical process of statistics which is directed to the transformation of the raw material into the tabular form, should be centralised or decentralised. This process is decentralised when the authorities charged with the returns themselves, or their subordinates, who only have to deal with the material from small districts, have to construct the statistical tables. On the other hand, the process is centralised when the collection of the raw material alone falls to the part of the subordinate servants of the administration, while the tabular treatment is handed over to the centres of statistical work.

Decentralisation is the older, centralisation the more modern method.

The advantages of centralisation are briefly the following:-The subordinate authorities are released from the task of constructing complicated statistical tables, which is very wearisome to them, and not at all suited to the nature of their regular business. By means of centralisation, those persons who have a real and constant interest in the proper treatment of the statistical materials, are reserved for the technical work of statistics. Further, by this method alone can that uniformity of treatment be secured, without which a proper working up of the material is not to be expected. Only by a supervision of this process by a statistical centre, can the full utilisation of the retarn, by the construction of tables with many subdivisions, be expected. Decentralisation in the making of statistical tables answers to production on a small scale, centralisation to production on a large scale.

In the latter case the principle of the division of labour is fully carried out, and insures the greatest uniformity, quantity and 
cheapness of production. The same is true in the case of the technical process of statistics. For instance, under centralisation, the method of treating the raw material by means of leaflets is quite in place, while it would lead to the greatest errors if it were applied separately by various administrative authorities who are not versed in this technical process.

On the other hand, it cannot be denied that centralisation brings with it certain disadvantages. The magnitude of the material which, on this plan, will arrive at the statistical centres, might be a hindrance to the careful testing and correction of the registers. Against this we may set the fact, that a central statistical office, which will have the greatest experience in regard to the errors and mistakes which occur in statistical returns, will most easily discover them. And this reflection will induce us to take care that there be no want of sufficient vigorous supervision of the raw material. Whether this purpose may be best effected in large countries, by means of the appointment of separate provincial offices, or by arming the central office with suitably increased powers, may be left undecided. A further disadvantage of centralisation is that the local peculiarities of the various parts of the country, are but little known to the central office. But a remedy for this may easily be found, in the introduction of assistants from the various districts, as well as in the use of information in writing. Moreover, even on the decentralised system, there is no guarantee that, at the sittings of the local authorities, more than one person, who is quite familiar with the circumstances of the district, will really take any trouble about the tables. If it is asserted that provincial officials will, if the technical work be centralised, lose sight of the facts concerning their own district, and be obliged to obtain them by a circuitous process, by means of the central statistical office, this assertion must be admitted. But the only requirements that will be affected are of small extent, and can be easily satisfied if those concerned really desire it. Finally, the question has been raised whether the directors of statistical offices, do not, under centralisation, lose in power of proceeding with their scientific labours. It is true that anxiety for the proper working of the statistical machinery, robs the manager of a central statistical office of many hours which would otherwise be quietly devoted to statistical inquiry. Nevertheless, I consider this drawback as much less than the advantage which arises from the constant handling of the original materials.

A discussion of the advantages and disadvantages of the centralisation of the technical processes of statistics, thus makes it clear that the balance is decidedly in favour of the former. The tendency which is observable in official statistics, towards extending this centralisation to departments over which it has not as yet obtained 
a hold, is a very right one. This presupposes, on the one hand, the complete separation of formulæ of collection from formulæ of concentration, that is, of the work of collection from the work of synthesis ; and, on the other hand, it presupposes that the statistical offices will be better supplied both with workers and with money.

Having concluded our remarks on the grouping of facts, as the second step of statistical operations, it now remains to glance at the work of reckoning, which is partly necessary for the immediate working up of the statistical raw material, and is partly required in subsequent operations.

The simplest arithmetical operation of which any extensive use is made in statistics is addition. Every primary statistical table whose columns are filled with absolute numbers, is the result of a series of additions. If the individual facts have been classified they must be added up, and finally there must usually follow a general summing up of the separate summations contained in the divisions of the table. If, for instance, we desire to obtain statistics of the age of the population, we classify the separate individuals, by means of the system of strokes, or that of leaflets, by single years. Then we add up the strokes or leaflets which belong to each year, and thus finally obtain a general total for the whole population. Correctly speaking, elementary statistics know of no other arithmetical operation than summation. But as soon as the further scientific treatment of the statistical material is included in our views, some other arithmetical operations come into prominence, which are so directly connected with the very existence of statistical tables, that it will be judicious to allude to them at once, although it cannot be denied that they form, to some extent, the point of commencement of the highest division of statistical work. These reckoning operations are:-

1. The striking of averages.

2. The obtaining of figures for oscillation or fluctuation, such as minima and maxima.

3. The attainment of relative or reduced figures.

The calculation of averages is so usual an accompaniment of statistical investigation, that even those who are not familiar with this department of knowledge, will easily imagine the endeavours of the statist to procure average numbers. Every average presupposes a series of observations, whether these follow one another in time, or are distributed in place. The average of a series of numbers, is that quantity which results, when the total result contained in the series is equally distributed among the members of the series. If, for instance, in any place, on the separate days of one week, there were born 14, 22, 24, 19, 1 3, 27, 2 I children, the figure 20 expresses a number of children born, which, if it had appeared 
regularly every day, would have given the same total, namely ${ }^{4}{ }^{\circ}$ children during the week. The number 20 is in this case called the daily average of births.

Arithmetically simple as is the process of striking an average, yet errors are of frequent occurrence in it. If, for instance, we find the average by dividing the sum of the series by the number of its members, we must take great care to have a right comprehension of what the number of the members is. Superficially many or several members will often appear condensed into one, which one member ought, in taking a correct average, to be counted as several. In other words, the similarity of the members must above all be secured. If, for instance, the grain market statistics of a place show, that 30,000 quintals of wheat were sold at 8 florins, and I, 000 quintals at 4 florins, and supposing the average price of wheat is to be obtained from this, we must remember that we have here not merely two observations, but taking account of similarity, a series of 31,000 observations, each of one quintal of wheat. The total price realised by the wheat, namely 244,000 florins, must therefore be divided by $3 \mathrm{I}, 000$. We thus get 7.87 florins. This is the true average price, and not 6 florins, the arithmetical mean of 8 and 4 . If we do not analyse the total into 31,000 distinct observations, we must at any rate be sure that each member of the series, as it appears superficially, shall be weighed, in reckoning the average, in accordance with its quantitative importance, i.e., in the present example, the price of 8 florins must be counted thirty times, and the price of 4 only once. This arithmetical result is the same as the last. In modern times, the average as corrected with regard to the relative importance of the separate terms of the series, is called the geometrical average, while that obtained without regard to this relative importance is called the arithmetical average. It is clear, that as far as possible, geometrical averages should be obtained. This mode of calculation is not, however, possible, in all cases, particularly when the relative importance of the members of a series is altogether unknown. When, for example, the average price of the means of subsistence for a particular year is to be calculated, the daily and weekly price of the article in question being known, but not the amount of the sales of it, we must be content with the arithmetical average.

A deeper insight into the nature of statistical averages is obtained, when it is realised that they fall into two groups which differ essentially in character. 1. The average may be a special type of circumstances and phenomena, which in their actual reality do not as a rule exactly correspond to this average result, but which approximate to it more or less closely, and in some cases absolutely coincide with it. For instance, if we have obtained the averages of 
the births and deaths in a certain country, for a period of twentyfive years, we may consider the averages obtained as types of the contingents of births and deaths respectively for each year. It is also not inconceivable, though not very likely, that in the twentysixth year these numbers should be exactly attained. On the other hand, it is highly probable, that the contingents for this latter year will, if no unusual events occur, approximate respectively to these average results.

To this class of statistical averages is opposed another group of average results, which we cannot speak of as supplying a type of phenomena, and which should rather be considered as abstractions obtained by reckoning. If, for instance, we find from the results of a census, that the average age of the population of a certain country is twenty-eight years, this is to all appearance, and as an arithmetical result, just as much an average as the yearly rate of births or deaths above mentioned; but in reality it is something totally different. An age of twenty-eight years is by no means typical of the ages of the persons of whom the population is composed; indeed it is quite inconceivable that a population should exist, whose members were as a rule twenty-eight or approximately twenty-eight years old. In this case the average result obtained is only an abstraction, which has nothing whatever in common with the real circumstances and phenomena.

It is scarcely necessary to adduce any further reasons, why, of these two groups of statistical averages, the first has a much higher claim to scientific consideration than the second. It need only be remarked here that averages which cannot be treated as types, must, for the purposes of science, be handled with great caution, if they are not to lead us to delusive conclusions. Since they are only arithmetical abstractions, they may, even in the case of identical results, arise from very different, or possibly from quite opposite, phenomena. The same average age might be obtained, for instance, for two countries, of which the one contained a large number of old persons and children, while the other was largely composed of persons in the prime of life.

A good illustration of the special value for statistics of the calculation of averages, has already been given as an introduction to the explanation of the geographical method of statistics. Here it need only be remembered, that the peculiar value of the average, in eliminating differences of time and place, consists in this, that instead of complex series of figures, which are hard to grasp in their scientific import, the average gives us a brief expression, with which it is much easier to work, and which offers a primary general insight into the actual condition of things.

Nevertheless, the discrepancy between the magnitude of the 
average, and those of the single results of observation, which vary in a thousand ways, is too great for the attainment of the average alone to be sufficient. A middle term, obtained from the calculations, is necessary, which does not coincide with the amount of the average, but renders the multiplex character of the series of observations scientifically comprehensible and comparable, by means of giving prominence to special points in them, and obtaining a short expression for the characteristics of the oscillations which therein manifest themselves. The obtaining of figures for oscillation or fluctuation, such as the minima and maxima of a series, serves this purpose.

The average obtained from a series of separate results, as has been remarked, certainly gives us a short expression, which is easily employed for further scientific work; but it is not by any means enough to give us a more profound knowledge of the statistically observed facts and phenomena. For this end it is necessary that a short expression should be obtained for the amount of the fluctuations above and below the average, which the separate results show. For instance, the same average may arise from two series of figures, which are entirely different as regards their fluctuations. This difference in amount of fluctuation, is, together with the average, of peculiar importance in determining the character of a statistical phenomenon. If we only look to the average, an important element is disregarded. As to the obtaining of identical averages from different separate results, the following example will suffice. Suppose that, in ten consecutive years, the number of births runs thus:-

In the Town of $\mathbf{A}$.
4,800
4,900
5,000
5,100
5,200
5,100
5,000
4,900
4,950
5,050

\begin{tabular}{|c} 
In the Town of B. \\
2,000 \\
3,000 \\
4,000 \\
5,000 \\
6,000 \\
7,000 \\
8,000 \\
9,000 \\
4,000 \\
2,000
\end{tabular}

Here the yearly average of births is, in each town, 5,000. But the statistics of birth for the town of A are certainly utterly different from those of the town of $B$, in spite of their having the same average during ten years. The latter town shows a considerable, the former only a moderate fluctuation, in its contingent of births. It is very important to obtain a short expression for the amount of this fluctuation, as compared with the average. The figure for oscillation or fluctuation supplies this requirement. It shows the 
average deviation of the separate results of a series of observations, from the general average of the series, and, for this purpose, is expressed as a percentage of this general average itself. If we wish to calculate the oscillation figure for the two series of numbers given above, we proceed as follows:-

The deviation from the yearly average $(5, \infty 00)$ in the ten separate years, runs thus :-

In the Town of A.
200
100
100
200
100
-
100
50
50
900

\begin{tabular}{|c} 
In the Town of B. \\
3,000 \\
2,000 \\
1,000 \\
1,000 \\
2,000 \\
3,000 \\
4,000 \\
1,000 \\
3,000 \\
20,000 \\
\hline
\end{tabular}

The average yearly deviation is, therefore, for A, 90, for B, 2,coo. Since the yearly average of the series is in each case 5,000 , the mean oscillation about the general average of the series, is, for $A$, only $I .8$ per cent.; for $B$, on the other hand, 40 per cent.

Since exponential figures are not required in statistical tables, the position reserved in mathematics for these figures can be utilised, in order to supplement those averages for which the mean oscillation is calculated, by the addition of figures for that purpose. In the present case, then, we shall simply say, that the yearly average of births amounts in the town of $A$, to $5,000^{1.8}$, while in the town of $\mathrm{B}$, on the other hand, it is $5,000^{40}$. We can then perceive at a glance that in these two towns we have to do with averages which are arithmetically identical, but in reality of very different natures. Especially we can at once judge, from the oscillation figure, whether the average obtained can be treated as approximately a type of the particular phenomenon. The smaller the oscillation figure is, the more is this the case ; and the larger it is, the less can the average be a type. The oscillation figure of any series can be obtained arithmetically; but it can only have statistical value on condition that the separate numbers of the series are similar. If we were to calculate the oscillation figure for the different numbers of births in the administrative districts of a country, this result would be worthless, on account of the unequal magnitude of these districts. We should first have to establish the requisite similarity among the members of the series, by a comparison of the births with the whole population, or perhaps with the 
number of women capable of bearing children. It will now be understood why the attainment of oscillation figures is peculiarly suited to series of ohservations which are periodical, and therefore bave the advantage of complete similarity as regards their separate parts.

It may be alleged against oscillation figures that similar averages combined with similar oscillation figures may be obtained from different sets of single fluctuations. This is true; but it may be replied, that in following out further the details of the fluctuations, we return to the separate study of the single members of the statistical series. This study will always retain its special value, and can besides be illustrated by the method of graphic representation in the case of series composed of many members. But our present object is to become acquainted with the reckoning processes which, by means of figures alone, subject the hardly manageable complexity of statistical series to quantitative determination. And, from this point of view, the value of oscillation figures is unassailable.

Nevertheless, it cannot be denied that it is also useful to obtain, and bring into prominence, the two members of a statistical series which represent the observed maximum and minimum. If this is done, we have in addition to the measure of average fluctuation included in the oscillation figure, the extreme superior and inferior limits, within which these fluctuations occur. In the above example, accordingly, we should have to supplement the average of births for the town of A, viz., $5,000^{1 \cdot 8}$, by the additional statement, " maximum, " 5,200 ; minimum 4,800;" and to supplement the average of births for the town of $\mathbf{B}$, viz., 5,000 ${ }^{\mathbf{4}}$, by the additional statement, "maximum, 9,000; minimum, 2,000." We may prefer, however, even in this case, to express the deviations of the maximum and minimum as percentages of the average, and to say, accordingly, "In $A$, the average of births is $5,000^{18}$; maximum 4 per cent, "minimum 4 per cent. In $B$, the average is $5,000^{40}$; maximum " 80 per cent., minimum 60 per cent."

The material value of an average can hardly be further elncidated by means of fignres, without impairing the clearness and intelligibleness of the conception.

The last group of reckoning operations, through which statistical tables must be prepared for further scientific use, consists in the evolving of relative or proportional numbers from the series of absolute numbers that have been obtained directly from the returns. The object of this operation is in all cases to render easy of comprehension the numerical relations which, in the primary absolute numbers, appear as minute quantities which are hardly available for purposes of comparison, by reducing them to simple numerical 
expressions, formed with special regard to multiples of the number 10. In so doing statists only make use of a method which is usually employed by business men, as, for instance, when the interest of a loan is stated not in terms of the amount of each item of accrued interest, but as a percentage of the capital lent.

Lastly, the proportional figures employed in statistics may be divided into two groups. We have a case belonging to the first of these when the members of a statistical series are to be made easily comparable with the total of the series. Let us suppose that in the country $A$, there are, out of 27,314 crimes, 1,900 in July and 2,789 for January, and in the country B, out of 76,2 18 crimes, 5, I I 7 occur in July and 7,639 in January. The rates for January, as compared with the total number of crimes for the year are $\frac{2,7 \mathrm{Sg}}{27,314}$ and $\frac{7.639}{76,218}$; those for July are $\frac{1,9000}{27,314}$ and $\frac{5,117}{76, \frac{1}{2} 18}$. From these numbers we certainly perceive that in both countries the January rate of criminality is considerably greater than that of July. But we cannot tell from these four vulgar fractions with numerators and denominators that are not powers of ten, how far the two countries A and B differ in this respect. We can, however, ascertain this at once if we transform each fraction into equivalent ones with decimal denominators, and call the rates of criminality for January $10^{\circ} 2$ and $10^{\circ} \circ$ per cent, and those for July $7^{\circ} \circ$ and 6.7 per cent. In these two cases the number 100 is adopted as the denominator. We might have chosen to represent the total, the components of which we desired to make easily available for comparison, by I, 10, 1, i.e., the expression of the relative amount of the parts by means of percentages is most common. So much is this the case that, by a misuse of language, percentages are spoken of even when some other round number than 100 forms the common denominator. Accuracy requires that in such cases we should speak of so many per mille, or per ten thousand. Besides, there are good reasons for the general employment of the method of percentages in the stricter sense. In most cases, where parts are compared with a whole, the number 100 is neither too large nor too small. It is only when we have to deal with a very long series of separate numbers of very various magnitudes that the numbers are reduced not to hundreds, but to thousands or tens of thousands. It may be added that, for purposes of comparison, it is of no importance which power of ten is chosen, since in changing the base we simply have to shift the point in the decimal fraction already found. On the other hand, it must be said, that the public whose dislike to rows of figures is great enough already, will be still more frightened away on finding that it no longer meets with totals, but tenths, or even hundredths or thousandths, in the form of decimal fractions. 
The second group of proportional figures occurs in statistics, when the object in view is not, as in the last case, the comparison of numbers representing parts with the total, but the comparison of figures, which have been given by different inquiries, with one another : as when the number of births is to be compared with the population, or the latter with the extent of land in cultivation. In this case also the operation is effected by taking one of the numbers to be compared as $=1$, 10, 100, 1,000, or some other power of ten, and then calculating the other. The most useful methods are, that of percentage, and of reducing to unity one of the numbers to be compared. For instance, if the country A shows 818,162 births in a population of $20,314,716$, we obtain $4^{\circ} 03$ births to every 100 inhabitants, or $24^{\circ} 95$ inhabitants to one birth. Both modes of expressing the fact are correct, but of late the preference has been given to the former. On this plan the rise and fall of the proportional figure takes place with the increase and decrease of the observed phenomenon (the frequency of births in the present case). On the other method of calculation the figure rises in value when the frequency of the phenomenon diminishes, and falls in value when it increases. In the above example the number gains in magnitude when births diminish and vice versâ. This produces a certain amount of confusion in the reading of statistical tables, and therefore the Congress at the Hague rightly declared in favour of the first mode of calculation.

The task of statistics is not yet completed when the facts of social life have been observed, the results obtained placed in the form of tables, and the further arithmetical treatment of these tables performed. There still remains a further labour to be gone through, which alone gives to statistical inquiry its full scientific value. If the information obtained by means of the returns themselves is the raw material, the tables may be regarded as the middle stage of the manufacture from which the finished scientific article is produced by further labour. This further scientific work consists in the demonstration of the conformity to law and order which exists in the mass of phenomena constituting the facts of social life. Certainly social life is a stranger to laws, that is, to physical laws in the narrowest and most definite sense of the term. The phenomena of society show a manifold variety in their subjective character as regards both time and space, which is wanting to physical laws in the strict sense. There are, however, in the realm of physics phenomena which resemble the facts of society considerably in this respect, and in which, therefore, we may perceive relations, which are not exactly laws properly so-called, but are nevertheless very important uniformities and regularities. The facts of meteorology distinctly belong to this class. The dis- 
cussion whether we ought to speak of "statistical laws" or merely of "uniformities" and "regularities" is a barren logomachy. If the regularity, or uniformity, is constantly so great that in a given case, under similar circumstances, the recurrence of a similar phenomenon is to be expected as in the highest degree probable, we are at liberty, even if mathematical certainty is not possible, to speak of a statistical law. In the case of inferior degrees of probability a more qualified expression is, no doubt, suitable.

At all events, the laws revealed by statistics are not laws concerning the future, but concerning the present and the past. The laws whose investigation is the highest work in the domain of statistics are not laws à priori, but experimental laws. They explain to us the whole phenomena as it appears when set free from the accidents which belong to the individual concrete phenomena. The laws of statistics are nothing but short general formulæ for expressing the apparently incomprehensible multiplicity of the phenomena of social life, and the actions and reactions which occur among those phenomena. A single example will suffice. Hardly anything is so uncertain for any individual as the time of the arrival of his own death. The greatest variety of causes are at work to determine this event, and frequently the actual approach of death is the consequence of blind chance. It would therefore be in vain to prophecy regarding the time of the decease of a single individual with any prospect of hitting the mark. But if the whole aggregate of individuals is put in the place of the individual, the case is altered. The apparent influence of chance is still powerful to affect the lives of individuals; but out of the combination of large masses of apparently irregular units there arises an image of regular organisation. We can definitely assert, on the ground of the most general experience, that a generation of beings born-say 100,000will, in the second year of their life, already have suffered a considerable diminution of numbers, and that it is absolutely impossible that the whole 100,000 should attain their tenth year. Further observations will show a more or less general regularity in the larger or smaller proportion lost from year to year by a generation as its age advances, until at length only isolated fragments of it are left, which will soon, in their turn, become the prey of death. That which is an inscrutable phenomenon in the case of a single individual, is a regular and easily cognizable phenomenon in the case of the aggregate. Death, the time of which cannot in ordinary cases be predicted for an individual with any certitude, takes place among masses of men in conformity with the well-ascertained course of the laws of mortality.

This regularity in the phenomena of the aggregate, side by side with a, to all appearance, complete want of regularity in those of 
the individuals is, moreover, not at all peculiar to the social life of man, but is exceedingly common in the realm of parely physical phenomena. One of the simplest examples that can be given is supplied by every fall of snow. The point at which any given snow-flake reaches the earth appears to be determined by pure chance, and yet the stratum of snow which we find after a fall, which has not been disturbed by the action of the wind, is of uniform thickness over wide surfaces. Of two adjacent square metres we do not find one heavily loaded with snow and another free from it. The phenomena are similar in the social life of man. Here, too, it is evident that the discovery of a certain probability regarding the occurrence of a given result, implies, as a matter of fact, a proportionate frequency in its actual occurrence. When this simple law of the social life of man was first discovered, and was found to hold even in the case of those acts which appear entirely arbitrary, people were astonished, since the new fact was not reconcilable with the ordinary conception of the freedom of the will. On a more careful consideration of the matter, it is plain that this regularity in the phenomena of aggregates is natural and self-evident, and that, on the other hand, want of regularity in these phenomena would be a cause of astonishment. Given a particular probability of an event, the natural law is the occurrence of this event in a similar proportion. In the case of the surface which is exposed to the fall of snow, there is an equal probability that adjacent square centimetres will be covered, just as there is the same probability of diminution by death for two different groups of a population, provided their physical and social conditions are identical. If the degree of probability has altered from what it formerly was, the similarity of results no longer holds. If a strong wind blows, the probability of being covered is greater for places protected from the wind than for those which are exposed to it, just as the mortality among the lower classes of the people, whose circumstances are unfavourable, is greater than that of the rich, who live in healthy dwellings. At a given hour of the day the traffic which passes through any given length of street may be expected to be constant under similar circumstances. All the inhabitants of the city will not, without some reason, either avoid the street at that particalar time, or throng to it in large numbers. The same number approximately will appear in it day after day. But if any unusual event occurs, such as a procession, which moves through the street in question, the regularity is gone. The events of social life, especially the volitional acts of men, are in the same category as a fall of snow and the traffic passing through a street.

I must specially point out, that in all cases of statistical laws it is necessary to treat the individual as an abstraction. Man only comes under our consideration as a mere fragment of the whole

VOL. XLVI. PART III. 
species. Statistical laws hold for the fragment, but as regards the individuals composing it they are a mere delusion. Each individual does not supply the quota of crime which he ought, according to the rate of criminality, to commit, and neither does he die on attaining the average age of man. During the process whereby an abstract statistical law is converted into. the concrete facts of the life of the individual the happiness and misery, volition and countervolition of these individuals is at work in infinitely various ways, without really much altering the net result. The statistical laws obtain their victims; only it is impossible to determine beforehand which of the individuals will be the victims; if one is not sacrificed, another is.

One of the most important efforts of modern statistics has been the investigation of the so-called "average man" in his physical and psychical relations. In reality, there is no "average man." If statistics could ever obtain a complete determination of him, he would form a general type of the infinitely various single phenomena belonging to the species man. The greater the extent of an observation of social phenomena, the more it possesses the character peculiar to statistics, and the more probable is it that the observation will lead to the establishing of a uniformity of social life, even if the law so discovered is not found to involve an unalterable fate for the individual man. The fact that aggregate observation is essential to this process is expressed by what is, with tolerable correctness, called the "law of large numbers." The nature of this law has been excellently stated by Süssmilch, the author of a work which appeared in the middle of the last century, entitled, "The " Divine Order in the changes occurring in the Human Race, " proved by means of the Births, Deaths, and Propagation of Man" kind." In the heading of Section 15 of the first chapter he says : "A peculiar characteristic of this order will be shown in that it " (the order) is concealed by the absence of order in small collec" tions of facts, and can only be brought to light by means of large " assemblages of lists obtained from numerous small places, and " during many years, and this is why it has remained unknown to "former philosophers."

Statistical laws may be divided into two groups. They are either (1) Laws of Existence and Development, or (2) Law's of Causation.

We meet with laws of existence and development, when we bring ont the typical effects of all causes which determine the character of one single specified phenomenon. If a single isolated group of facts forms the subject of the observation, the law investigated is one of existence. If it is a case of a succession of facts of the same kind, the law to be determined is one of development. The law which 
regulates the numerical proportions of the two sexes, and of the different classes of ages, in regard to criminality, is a law of existence. On the other hand, if we examine into the law of mortality, that is, investigate the constant diminution of a generation of persons born, or of persons now at a given age, we have a law of development.

Laws of causation are those which assert that two distinct phenomena which have been statistically determined are related to one another as cause and effect. For instance, if there is a c.snstant connection between the price of grain and the amount of crime, we have a statistical law of causation.

These two kinds of statistical laws occur, as we have already shown, both in the case of phenomena independent of the human will, and especially in the case of those actions which are arbitrarily determined. The study of the laws which govern these latter is of the highest general interest. Statistics have undoubtedly established here an entirely new basis for the proper comprehension of "free will."

Having now described the three stages of statistical inquiry, it remains only to examine the means of representing statistical results. If these were only numerals and language, no explanation would be required. But of late the graphic representation of statistical results has been making more and more way. This method is most advantageously employed in the popularisation of statistics, and on this account deserves a special consideration.

But it may be as well to deal briefly with numerals and language as means of representing statistical results. The original form of statistics is the numeral, which is absolutely essential, since without numerals there can be no statistics in the modern sense. The numerals, however, are not given in a confused mass, but in the form of well-arranged tables. These tables give the quantitative results of aggregate-observation completely and comprehensively grouped, with proper regard to the facts which form the basis of classification. The tabular form is looked upon with unreasonable dislike by the reading public. This is because the study of tables demands concentrated thought, while the public prefer thought diluted by phrases.

That the science of statistics cannot dispense with words is obvious. We only make special mention of language as a means of representation in statistics, because formerly, especially in official circles, the general opinion was that statistics ought to produce numerals and nothing else. At the present time there is scarcely anyone who seriously shares this narrow notion. When official statistical tables first began to be published, there was some 
excuse for the notion that non-official cultivators of the science would seize on the newly won material with enthusiasm, and make use of it in many ways. The lapse of time has cured the official statist of this delusion, by showing him that statistics composed solely of numerals are only still-births. The statist who conducts the inquiry and undertakes the construction of the tables, is bound to use his numerals for the purposes of science, and to perform the work of criticising them himself. And this of course is impossible without verbal explanation. If the statist will not himself enter the sea of figures he has placed before the public, he cannot be surprised if the public, who are little acquainted with the depths and shallows of this ocean, are from the first frightened away from it, and pay no further attention to the colnmos of figures which are presented to them.

The method of Graphic Representation requires a fuller explanation than is required for numerals and words.

The graphic method includes both the simple geometrical representation of statistical figures, the Diagram, and the representation of statistical relations on maps, the Cartogram. These two classes of graphic representation are essentially different, and it is necessary therefore to deal with them separately.

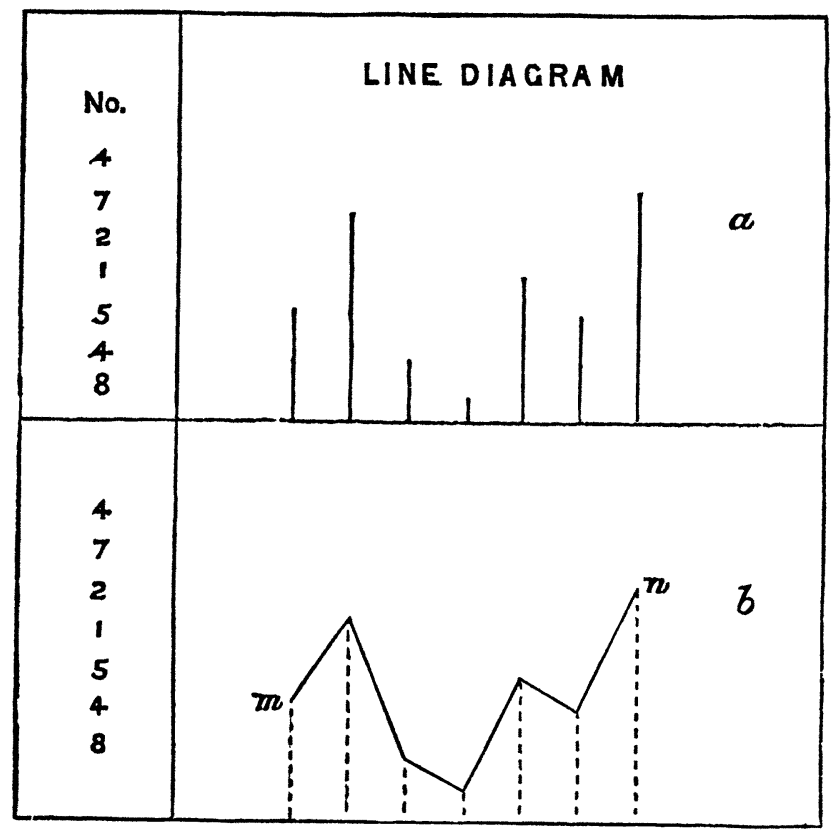

Fig. 1.

I. Diagrams.-The geometrical conceptions at the disposal of 
statistics are the point, line, surface, and solid. Of these the point is obviously of no use in diagrams proper. But if we combine topographical representation with the diagram, that is, combine the cartogram with the diagram, the point obtains a significance, as will be subsequently shown.

(1.) The Line.-The line may be employed in diagrams in two ways; we may have, first, straight lines of different lengths ; and, secondly, lines joining the terminal points of such lines. In such cases a regard for clearness makes us choose straight lines, and for the same reason we select parallel lines drawn at right angles to a fixed base.

The first of these (Fig. 1, a) is too wanting in clearness to be of much value, especially as the end in view can be much better attained by the use of surfaces placed in juxtaposition. Thus-

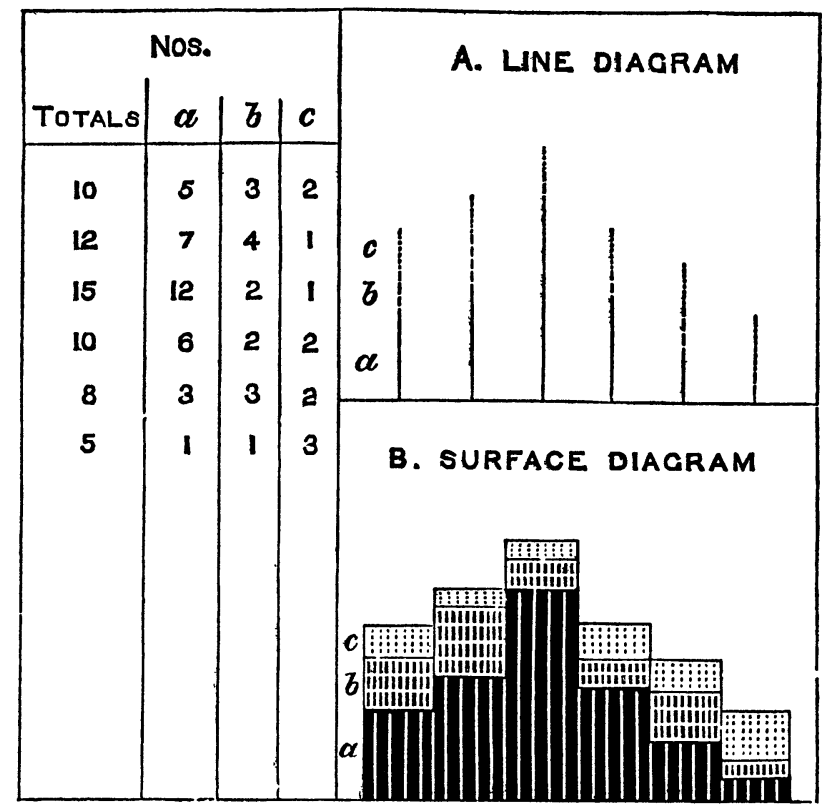

Fig. 2.

In this diagram, the breadth of the surfaces gives the eye rest, and it obtains the guidance which is desirable, from the series of steps produced by the juxtaposition of the different surfaces. The use of surfaces in juxtaposition is further advantageous, since by them we can show internal differences among the totals represented, much more easily and clearly. Lines cannot be so easily distinguished in their parts, by means of variations of colour and shading, as surfaces. This is obvious in a comparison of $A$ and $B$ (Fig. 2). 
It therefore appears that the mere juxtaposition of straight lines of various lengths is not enough to form a line diagram. The other class of such diagrams, which are formed by joining the extremities of the various lines are more useful. Line diagrams of this kind, which are often, though not always correctly, called "curves," have been employed much and in various ways, and will always continue to be a valuable assistance in the graphic representation of statistics.

The advantage of this kind of line diagram is chiefly this: it affords the eye a simple and sure guide in following the rise and fall of numerical relations. In addition, it has the further advantage of taking up a minimum portion of the space devoted to graphic representation, and therefore enables us to place in the same linear system one or more comparison diagrams. We may, for instance, represent the mortality, birth-rate, price of grain, and changes of temperature, in one diagram, containing four lines for comparison among themselves. Comparative diagrams of this kind composed of lines which can be made easily distinguishable, by the use of colours, or dots, or breaks in their course, and similar devices, materially facilitate the investigation of parallelisms or antagonisms between different phenomena. They are therefore of interest not merely to the consumers of statistics, as mere illustrations of statistical figures, but also to their producers, by the aid they afford to comparative inquiry.

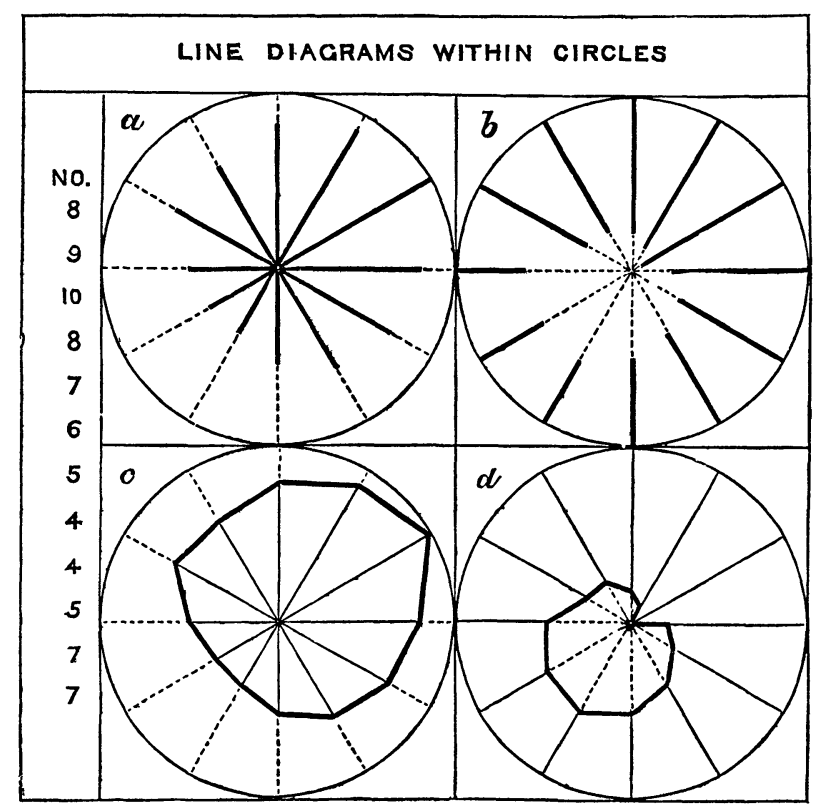

Fig. 3. 
Line diagrams of the akove kind are advantageously employed when it is our object to examine merely the members of a series of statistical figures, which do not clange in their essential character, and which vary at stated intervals. For instance, they are well suited for the representation of the history of the prices of specified commodities, the yearly variation in the number of deaths, crimes, and so on.

For the purpose of representing facts which actually form a cycle, a line diagram based on a circle may sometimes be employed, for instance, when we desire to represent the death-rate of each month, not during a single year, but by means of the average of each month taken over a series of years. In this case, January is as near to December as to February, a fact which cannot be represented except by taking a circle as the basis of the diagrams. Portions of radii, measured either from the centre or from the circumference, form the lines whose length is made proportional to the numerals (Fig. 3).

(2.) Surfaces.- The point diagram is of hardly any use, and the line diagram is only available in certain circumstances. All other statistical relations which we desire to illustrate by diagrams, must be represented by surface diagrams, for the employment of solids is impracticable, in literature, at all events.

As previously observed, a great advantage of surface diagrams is, that they admit of a complete representation of the internal composition of the statistical quantities placed before us. But the representation of various details should not be carried too far, or a mistake will be made similar to that committed in a line diagram, where the lines to be compared are too numerous and intersect one another.

The conditions under which surface diagrams are suited to the purpose they are intended to serve, are the following :-

The figures chosen must be simple. For the representation of the composition of simple totals, the most suitable figure is the square, which can be divided into the proper number of rectangles.

If several statistical facts are to be united for comparison by means of a surface diagram, the most convenient figure is the rectangle. We may employ either rectangles with equal bases and varying altitudes, or rectangles with varying bases and the same altitude. The first of these is the more easily comprehended. It is closely allied in character to the line diagram, and can always be used to supplement the latter, when it is desirable to represent the internal grouping of the separate facts expressed by it. Such surface diagrams are much used. It very materially adds to the clearness of these diagrams, if the squares of the system 
of cross lines in which the rectangles are drawn, are so arranged as to represent either unity, or some decimal part of it.

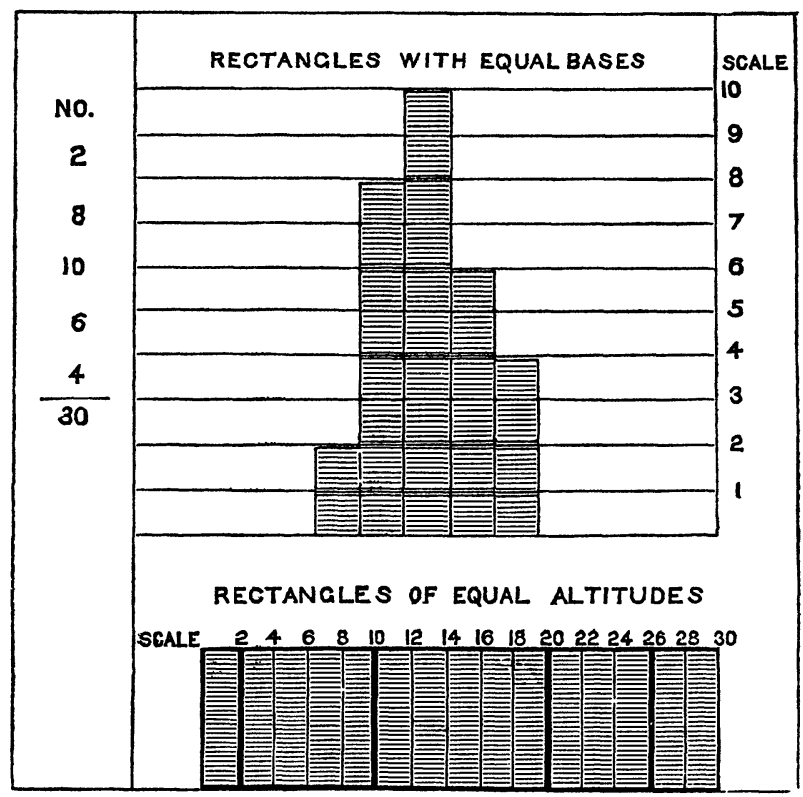

Fig. 4.

No other figures besides rectangles are suitable, except that in cortain cases (although the employment of triangles in such a diagram as the above is useless) a single triangle may be advantageously employed to represent facts which are composed in special ways; for instance, when we desire to contrast a qualitatively important minority with a qualitatively inferior majority.

The triangle is the form especially suited for diagrams when the parts of a total to be represented form a qualitatively ascending series, as for instance the state of public instruction, beginning with the national schools and rising to the highest class of schools.

By dividing the triangle horizontally, as in Fig. 5, B, the level of the surfaces is progressively rising as they approach the vertex, and the statistical relations to be represented are well marked, without affecting the proportions between the parts. If it were attempted to show the same relations by means of a square, the qualitatively important but quantitatively insignificant minority would almost entirely disappear (see Fig. 5, A).

No other figures are practically suited to our purpose. It should be roticed, with regard to the use of surface-diagrams, that they admit of the most extensive application of colouring and 
shading, as a means of distinguishing the separate diagrams and their different parts. In particular, a judicious use of colours and shading renders it possible to give expression to many facts in a single diagram. Care must, however, be taken that the diagram may not become artificial and hard to understand.

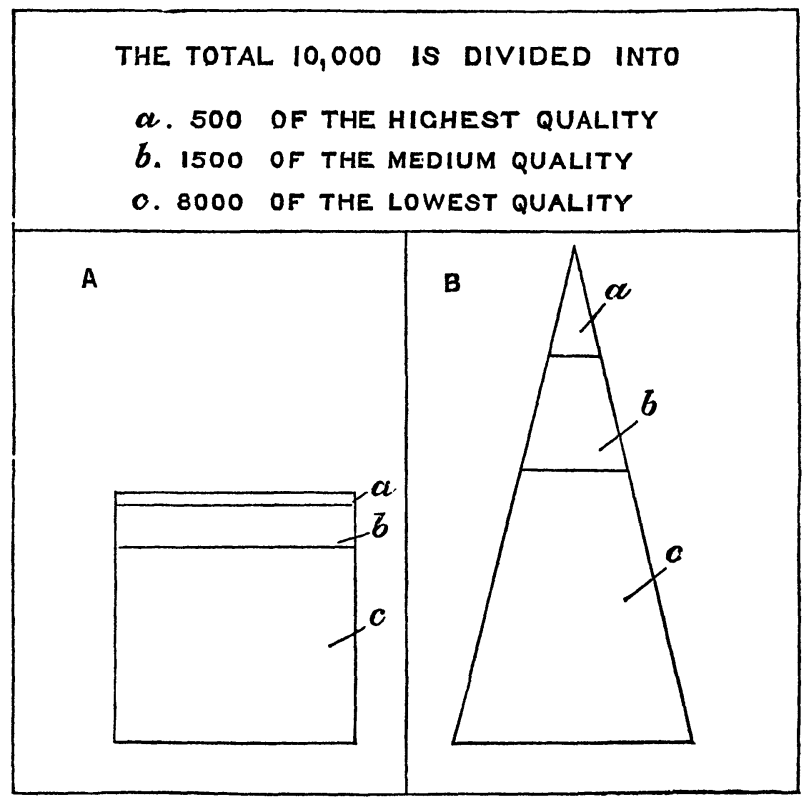

rig. 5.

The employment of solids does not concern us for the purpose now in view.

II. Cartograms.-The cartogram is essentially different from the diagram in that it is not merely a means of making the numerical facts given in tables perceptible to the senses, but contains something else which the tables cannot represent. This new feature, which in the cartogram attaches itself to the numerical facts contained in the table, is the introduction of the topographical disposition of the statistical facts, which can never be grasped sufficiently by means of the table alone. The peculiarities of the cartogram therefore supply a real improvement, and not merely a secondary means of illustrating statistical results. The scientific value of cartograms is therefore much higher than that of diagrams.

Since we must include, under the head of cartograms in the wider sense, all forms of the topographical representation of statistical results, we have to consider the following kinds of cartogram.

1. Cartograms in which only points are employed to represent 
special facts detcrmined statistically (the point cartogram). This primitive form of cartogram has been long in use in maps, especially for the purpose of representing the statistical facts, in particular those of population, which are shown in maps together with the purely physical features of the country. We are, of course, not thinking here of points in a strict sense, but include all hieroglyphic or conventional signs used in map making, which denote special facts of a simple kind, without giving their quantitative relations. It is worth noting that in the traditional hieroglyphics of ordinary maps there are here and there traces of an attempt to form topographical diagrams. This is especially the case with the signs for populous places, great cities in particular, which in ordinary maps usually bear some relation, however rough, to the number of the inhabitants of the place.

2. Cartograms on which statistical facts are represented by lines (line cartograms), cannot easily be employed as a rule, for in all cases where our object is to represent the geographical distribution of statistical facts, surfaces are much preferable to lines.

3. Representation by means of surfaces is of great importance in statistical cartography. Surface cartograms are divided into three sub-classes: A.-Cartograms with surface diagrams in their proper geographical position. B.-Cartograms with bands showing the local movements of aggregates. C.-Cartograms in which statistical averages calculated for whole sections of a district are represented on a special plan of grouping, by means of colours or shading.

A. Cartograms with simple surface diagrams in their proper geographical position, are merely maps of the ordinary kind with statistical additions. The social facts which on ordinary maps only appear as supplementing the signs relating to the physical features of the country, without being represented quantitatively, are in this kind of cartogram clearly marked both in number and proportion.

Since all that is required in this case is to distribute the surface diagrams above described in their proper geographical positions, there is nothing special to say about the construction of this class of cartogram.

B. Cartograms with bands, showing the local movements of aggregates, are maps of means of communication illustrated statistically. For instance, while ordinary maps only show the direction of a railway line, a band-diagram gives in addition quantitative information regarding the passenger or goods traffic. The mode of representing these facts is simple, and its nature easily seen in Fig. 6.

At the starting point of the traffic a line of a convenient length is taken on which to represent the value or amount of the 
aggregates moved; there should also be some means of distinguishing between the different kinds of traffic. Every increase or decrease of the quantity transported is to be represented at each station where it occurs by a line proportional to that first chosen. These lines should be, as far as possible, perpendicular to the main traffic line. Lastly, these single lines at the separate stations should be joined, thus producing a series of bands, each of the same breadth as the line drawn at the successive stations, and extending as far as the next line, which bands should be coloured or shaded.

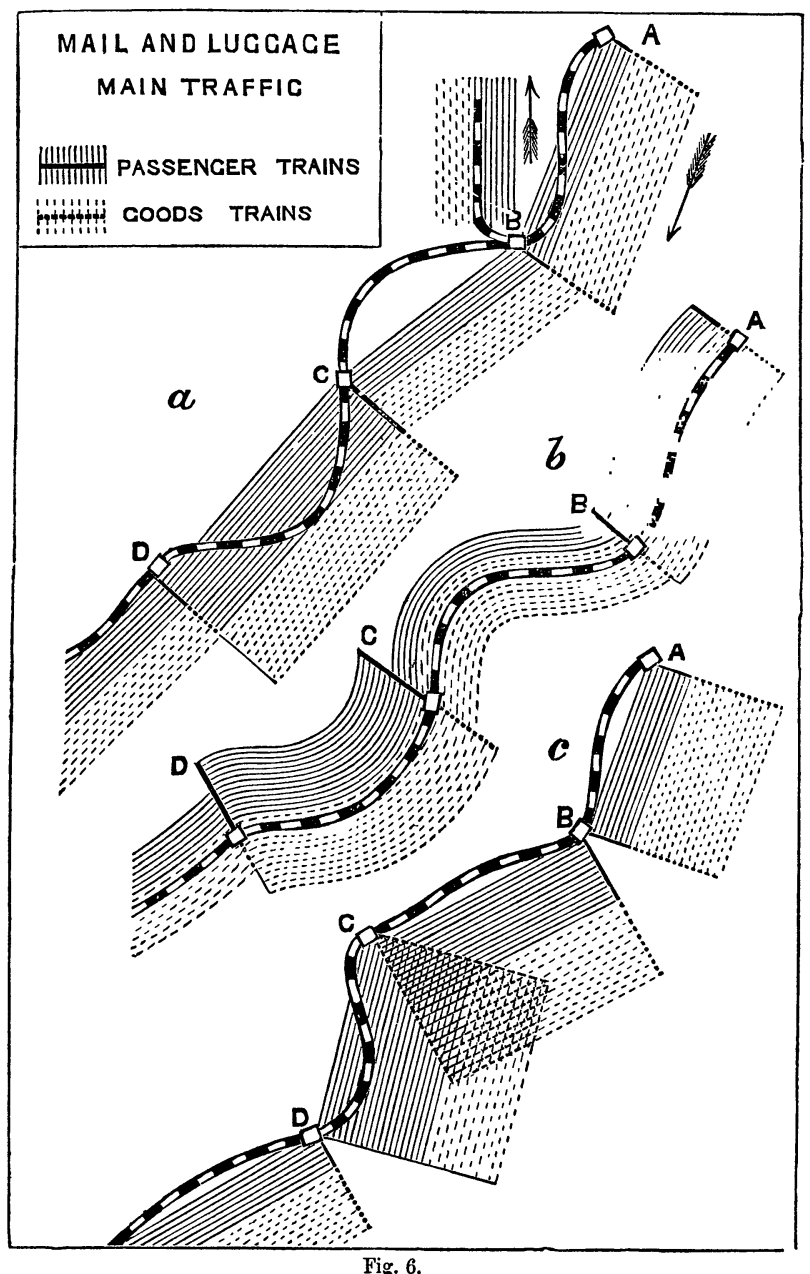

This surface-diagram is only mathematically correct when the traffic roads are straight. Where curves occur errors are intro- 
duced, and the surfaces are no longer proportional to the produce of the quantity moved into the distance traversed. If the continuity of the bands is to be maintained, this defect cannot be avoided, whether, as in Fig. A, we choose to ignore the curves between the separate stations, or whether, as in Fig. B, we allow the bands to follow the course of the traffic route. If we break the continuity of the bands at the points where curves occur, and then construct rectangles on the lines belonging to each station, whose height is determined by its distance from the next station, the representation is then correct mathematically. But the breaking up of the continuity of the bands, and the overlapping which takes place in consequence, is rather confusing at first sight. Fig. 6, B, presents in any case the best appearance.

C. Cartograms in which statistical averages calculated for whole sections of a district are represented on a special plan of grouping, by means of colouring or shading, are statistical maps in the less wide sense. They are the most important aid to the geographical method above described, which attempts to obtain the actual grouping of certain facts in the large natural districts, on the basis of statistical averages determined for smaller districts.

Since in this case the basis of the graphic representation is formed by districts which are very various in their geographical character, and which especially differ from one another in form and area, it is evident that statistical facts can only be cartographically represented on this method by relative numbers. By this means the separate dissimilar areas obtain the similarity which is requisite for statistical compariscns. All other forms of diagrams and cartograms which we have thus far explained, are in theory as well suited to represent absolute as well as relative numbers.

If the cartograms here referred to are to be of any value, the sections of country which are being measured out with a view to the statistical facts in question, must be chosen, so as to be the smallest possible, with due regard to the law of large numbers. The question of grouping is also important. The grouping is most perfect when we take the difference of the general maximum and minimum, and divide this difference by the number of the groups which disclose themselves. From this we obtain the limits of each group in the scale.

It is also necessary in practice to consider how colouring and shading are to be employed in arranging the single districts in the groups selected. The use of shading alone is not sufficient, when any considerable number of groups is to be represented. In the case of four or five groups, the differences can be made easily obvious by means of shading; but when the number rises to eight or ten groups such delicate differences become requisite, that the 
clearness of the picture is destroyed. And the same objection applies to the employment of a considerable number of colours. Whatever series of colours is chosen, as soon as the observer has to make use of a long scale of colour, the cartogram becomes difficult to comprehend. The best plan, therefore, is to combine colour and shading. Two colours may, for instance, be chosen, and then by the use of four or five kinds of shading we obtain the means of easily distinguishing eight or ten groups. As an example we may refer to Fig. 7,* which is a portion of a map of the infant mortality of South Germany for the year 1870, taken from the "Zeitschrift" of the Royal Statistical Bureau of Bavaria. Maps which are to be used as a basis for the application of this method must show the boundaries and names of each district with sufficient olearness. It is open to question whether they should contain further geographical indications, and if so to what extent. Excessive details speedily destroy the clearness of the shaded colours. On the other hand, the complete absence of geographical indications renders impossible the making of orographical and hydrographical comparisons, which are much to be desired on their own account. Hence the positions of the principal rivers and mountains should be added, always provided that the working out of these geographical signs in practice does not interfere to any extent with the clearness of the shaded colours which are to be superposed on them.

If we have, in the foregoing pages, treated at some length of the theory and construction of statistical diagrams, we are justified in so doing for the purposes of the present work, because cartographical representations are pre-eminently suited for making the results of statistics easily and generally understood.

The close relations which exist between statistics and the State have been already explained. A final remark as to how these relations have become patent to all, through the organisation and development of official statistics, will not be without interest for some of our readers.

The knowledge that the most important objects of statistics cannot be carried to their completion without the aid of State intervention was diffused tolerably soon, but the attempt to organize these official statistics was made much later, and is by no means concluded yet.

We may distinguish three periods in the development of official statistics, which, however, are not separated from one another in all respects with equal clearness.

In the first period, which includes the latter half of the pre-

* It has not been thought necessary to reproduce this diagram, which is in two colours, each of four shades. 
ceding century and the earlier years of the present, the need for official statistical information began to make itself felt. The practical methods of collecting statistics were then quite simple. The specific localities concerning which information was to be given were decided on by the central Government of the State, but no trouble was taken with regard to the method of collection. The inferior political officials had charge of the process of observation and of the whole work of grouping the facts, and were originally left without the guidance of any fixed and uniform rules for the operation. In the rarest cases only do we meet with any further treatment of the information obtained, with a view to practical or scientific objects. Generally, the authorities were contented with mechanically adding up the totals received from each province to obtain that of the whole country. The publication of official statistical information was, as a rule, forbidden, and was only permitted under special safeguards. Statistical tables were part of the secrets of the State.

The second period may be considered to commence with the establishment of special statistical bureaux. The masses of statistical information which had been collected during the first period could no longer be dealt with by the central authorities, and in particular by the political administration. Tables were heaped on tables, and there was no one to inspire the rows of figures with life. Accordingly statistical bureaux were established. At first their domain was very contracted; very often they were expressly confined to the business sphere of a single administrative department. Moreover, they had no control whatever over the management of the process of collecting statistics. Generally speaking, the inferior officials were still left in charge not merely of the collection, but also of the statistical treatment of the observed facts. The statistical bureaux had, in fact, only to attend to the final concentration and revision of the materials which were already arranged in the tabular form by subordinate officials, and at the same time to superintend their publication. How far this work of publication was combined with a further practical and scientific appreciation of the results obtained, would depend entirely on the personal character of the directors of the official statistical bureaux.

In general, the field of operations of statistical bureaux during the second period was not very extensive; but in it may be discerned the germ of the development which occurred during the third and most recent period in the history of official statistics.

This development is not merely a movement of extension, by which new regions, hitherto not subjected to aggregate-observation, are included in statistics, but it is above all an internal change, which expresses itself in the continual improvement in the technical 
part of statistics. Now, for the first time, we find effected that careful separation, described minutely above, between the collection of statistical facts on the one side, and the treatment of the material thus obtained on the other. Now that this latter operation is performed in special statistical workshops, viz., the statistical bureaux, it has been carried to a pitch of perfection hitherto unknown. The art of statistical combination, has especially shown a flourishing growth in its improved modes of constructing and employing complicated tabular work.

At the same time there is an evident tendency to allow official statistics to step beyond the peculiar domain reserved to bureaucracy. Attempts are made to induce the public to lend their active co-operation in the most important statistical inquiries, especially in the case of a census. It is not considered enough to leave the filling up of the numeration papers to the heads of families alone, but volunteers are sought for to whom is entrusted the honorary office of a numerator.

In order to reduce the process of collecting statistics in each country to uniformity, so-called central statistical commissions were established almost everywhere, in accordance with the example of Belgium. They were composed of delegates from the various centres of administration, especially the various ministers of State, as well as of the heads of the statistical bureaux, and of men of science specially invited to assist.

Simultaneously an attempt was being made by means of international statistical congresses to render comparable the statistics collected in the various countries of the civilized world. Although this end has, as yet, not been completely obtained in all respects, yet the advance that has been made in statistical science by means of these congresses is very remarkable. The first took place in 1853 in Brussels, at the suggestion of the veteran Quetelet. Since then international congresses of statistics have assembled in Paris (1855), Vienna (1857), London (1860), Berlin (1863), Florence (1867), The Hague (1869), St. Petersburg (1872), and BudaPesth (1876). One remarkable feature of these congresses is the co-operation of consumers with the producers of statistics. The "producers" are the official statistical delegates sent to these congresses by the different Governments. The men of science take part in the congress in concert with the officials, being interested as "consumers" in the labours of the latter. Under the pressure exercised by the "consumers," who as a rule are very numerously represented at the congresses, the resolutions of these assemblies are often marked by a profusion of demands on the official statistical establishments, which extends beyond the limits of the attainable. This circumstance was one of the causes which led to 
[Sept.

the establishment, at the congress of St. Petersbarg, of a permanent commission of international statistical congresses, composed exclusively of "producers." To this commission is entrusted the management of comparative international statistics, and of the revision of resolutions of the congresses, which is for this purpose highly desirable. It has already met in Vienna (1873), in Stockholm (1874), in Buda-Pesth (1876), and in Rome (1877).

As another special sign of the high degree of interest that has recently been aroused by official statistics, it is especially worth noting, that the great cities are more and more feeling the need of establishing special bureaux of municipal statistics. 